\title{
Lifecycle Prognostics Architecture for Selected High-Cost Active Components
}

N. Lybeck

B. Pham

M. Tawfik

J. B. Coble

R. M. Meyer

P. Ramuhalli

L. J. Bond

August 2011

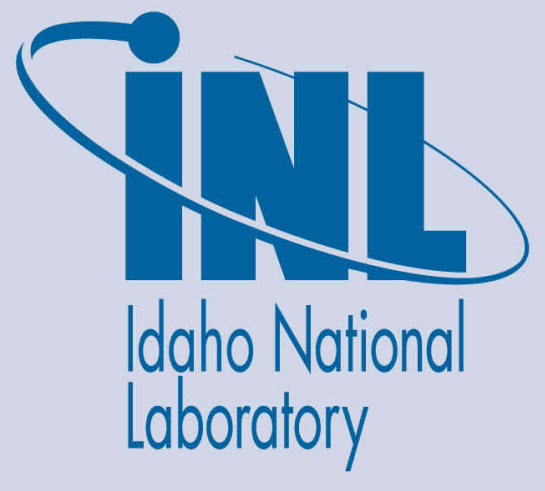

The INL is a U.S. Department of Energy National Laboratory operated by Battelle Energy Alliance 
INL/EXT-11-22915

\title{
Lifecycle Prognostics Architecture for Selected High- Cost Active Components
}

\author{
N. Lybeck \\ B. Pham \\ M. Tawfik \\ J. B. Coble ${ }^{1}$ \\ R. M. Meyer ${ }^{1}$ \\ P. Ramuhalli ${ }^{1}$ \\ L. J. Bond ${ }^{1}$ \\ ${ }^{1}$ Pacific Northwest National Laboratory
}

August 2011

\section{Idaho National Laboratory \\ Idaho Falls, Idaho 83415}

http://www.inl.gov

Prepared for the U.S. Department of Energy Office of Nuclear Energy Under DOE Idaho Operations Office

Contract DE-AC07-05ID14517 


\section{DISCLAIMER}

This information was prepared as an account of work sponsored by an agency of the U.S. Government. Neither the U.S. Government nor any agency thereof, nor any of their employees, makes any warranty, expressed or implied, or assumes any legal liability or responsibility for the accuracy, completeness, or usefulness, of any information, apparatus, product, or process disclosed, or represents that its use would not infringe privately owned rights. References herein to any specific commercial product, process, or service by trade name, trade mark, manufacturer, or otherwise, does not necessarily constitute or imply its endorsement, recommendation, or favoring by the U.S. Government or any agency thereof. The views and opinions of authors expressed herein do not necessarily state or reflect those of the U.S. Government or any agency thereof. 



\begin{abstract}
There are an extensive body of knowledge and some commercial products available for calculating prognostics, remaining useful life, and damage index parameters. The application of these technologies within the nuclear power community is still in its infancy. Online monitoring and condition-based maintenance is seeing increasing acceptance and deployment, and these activities provide the technological bases for expanding to add predictive/prognostics capabilities. In looking to deploy prognostics there are three key aspects of systems that are presented and discussed: component/system/structure selection, prognostic algorithms, and prognostics architectures. Criteria are presented for component selection: feasibility, failure probability, consequences of failure, and benefits of the prognostics and health management (PHM) system. The basis and methods commonly used for prognostics algorithms are reviewed and summarized. Criteria for evaluating PHM architectures are presented: open, modular architecture; platform independence; graphical user interface for system development and/or results viewing; web-enabled tools; scalability; and standards compatibility.

Thirteen software products were identified and discussed in the context of being potentially useful for deployment in a PHM program applied to systems in a nuclear power plant (NPP). These products were evaluated by using information available from company websites, product brochures, fact sheets, scholarly publications, and direct communication with vendors. The thirteen products were classified into four groups of software: research tools, PHM system development tools, deployable architectures, and peripheral tools. Eight software tools fell into the deployable architectures category. Of those eight, only two employ all six modules of a full PHM system. Five systems did not offer prognostic estimates, and one system employed the full health monitoring suite but lacked operations and maintenance support. Each product is briefly described in Appendix A, "Assessment Criteria." Selection of the most appropriate software package for a particular application will depend on the chosen component, system, or structure. Ongoing research will determine the most appropriate choices for a successful demonstration of PHM systems in aging NPPs.
\end{abstract}




\section{SUMMARY}

At the start of 2011, there were 439 nuclear power plants (NPPs) in the commercial global fleet; these plants started operation with 30- or 40-year licenses. The 104 NPPs in the United States represent about 10\% of the installed capacity and currently provide about $20 \%$ of U.S. electricity. They have become highly efficient with an average capacity factor in excess of $91 \%$, and they are a key element in the delivery of base-load electricity. They were originally licensed for 40 years, and a process has been established to enable license extension, to permit operation from 40 to 60 years. As of July 2011, license extensions have been granted for 71 plants at 40 sites. An additional 13 plants at nine sites are currently undergoing review for license extension to 60 years, and 19 more submissions are expected in the next 6 years. Nine plants in the U.S. have now moved into extended operation (past 40 years).

To meet the ever-increasing energy demand, the United States nuclear industry is now investigating the possibility of longer-term operation, from 60 to 80 years, for the existing NPP fleet, and is developing new plants with longer design life. The safe, secure, reliable, and economic extended operation of aging NPPs presents many challenges. The 2009 Light Water Reactor Sustainability (LWRS) Workshop identified online monitoring (OLM)of active and structural components as essential to the better understanding and management of the challenges posed by aging NPPs. Operators of aging NPPs need condition information to better manage plant life holistically, adjusting operating conditions to reduce the impact of stressors. All of the trends seen for operating the legacy and the new nuclear power fleet are increasing the needs for the application of advanced online surveillance, diagnostic, and prognostic techniques to continuously monitor and assess the health of NPP systems and components. The use of OLM for fault diagnosis enables the use of ConditionBased Maintenance (CBM), a regime where components are replaced or repaired based on condition rather than age. Active components, including pumps, valves and motors, are now being well managed and replaced as necessary using CBM. However, there are opportunities to move beyond anomaly detection in assessing condition. Other industries are employing tools that can predict condition, rates of degradation, and remaining useful life. These insights enable more costeffective plant management, allowing components to be managed and replaced based on the estimated time of failure.

Implementation of advanced condition monitoring and prognostics in existing NPPs poses many challenges, and it can be expected that it will initially be demonstrated with little to no additional sensing capabilities. The Electric Power Research Institute (EPRI) has already demonstrated the feasibility of OLM, in various forms, at several participating U.S. NPPs, including Harris, Limerick, Salem, Sequoyah, Three Mile Island, and V. C. Summer. Additionally, OLM has been implemented in Europe, both at British Sizewell B and at several Electricité de France nuclear facilities. Base technologies, including wireless data infrastructures, are being installed in an increasing number of plants. The next step in the development of advanced OLM is to move beyond condition-based maintenance with pattern recognition and anomaly detection applied to the measured data. This next development is to provide an estimate for the remaining useful life using prognostic tools. 
This report provides an assessment of the state of the art technologies needed for the application of prognostic tools to high-value active components in NPP. Three areas are discussed:

- Component selection methodology

- Prognostic algorithms

- Prognostics architectures.

In selection of components for the application of prognostic, as attention turns to longer term operation, interest is increasing in understanding the fundamental degradation signatures, and their impact on a system or component. A set of criteria is presented that will guide selection of systems, structures, and components, which are viable targets for prognostics and health management (PHM). Time and resources would be wasted developing PHM systems for components that represent low risk to the plant (the product of probability of failure and consequence of failure) because these components will not illustrate the true benefits of PHM. The choice of components and systems to be monitored is critical to economic viability.

A number of prognostic algorithms have been developed and successfully demonstrated in other industries, and the scientific basis for applying advanced diagnostic and prognostic systems for active component monitoring has been established. A challenge will be adapting and validating these methods to NPPs. Knowledge of the broad array of available prognostic algorithms is necessary to select the most effective models for each selected component. An existing software framework can be leveraged to demonstrate the use of PHM in an existing NPP with reduced development time and cost.

Finally, a review of commercially available PHM software products is given. Thirteen products identified through literature and Internet searches are evaluated based on a consistent set of criteria: open, modular architecture; platform independence; graphical user interface for system development and/or results viewing; web-enabled tools; scalability; and standards compatibility. The thirteen products were classified into four groups: research tools, PHM system development tools, deployable architectures, and peripheral tools. Eight software tools fell into the deployable architectures category. Of those eight, only two employ all six modules of a full PHM system. Five systems did not offer prognostic estimates, and one system employed the full health monitoring suite, but lacked operations and maintenance support. In looking towards potential for deployment, if an existing software framework can be leveraged to demonstrate the use of PHM in an existing NPP this will reduce development time and cost. 


\section{CONTENTS}

ABSTRACT.

SUMMARY $\mathrm{V}$

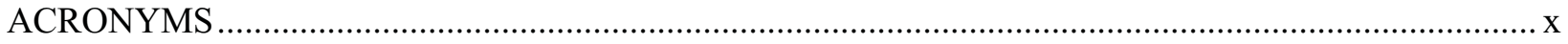

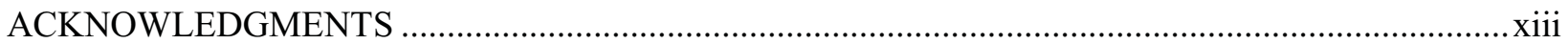

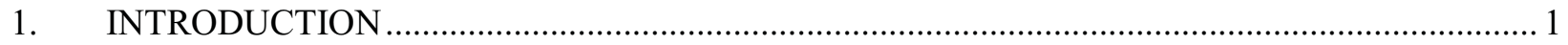

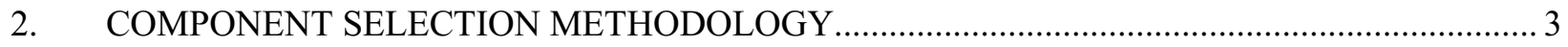

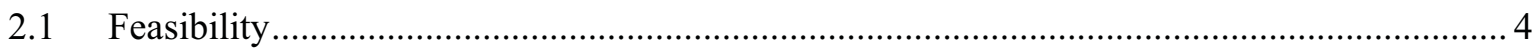

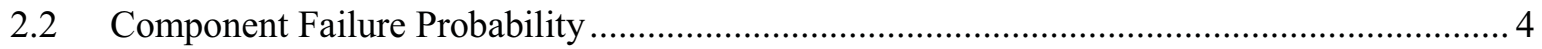

2.3 Consequences Associated with Component Failure ...................................................... 5

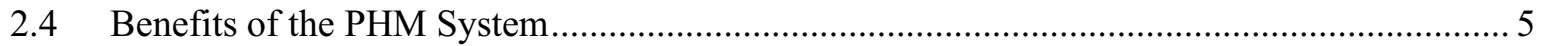

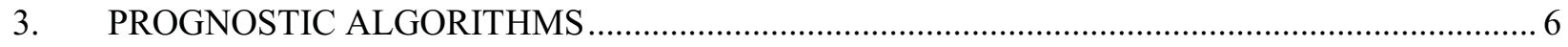

3.1 Type-I Prognostic Models: Traditional Time-to-Failure Analysis ..................................... 9

3.2 Type-II Prognostic Models: Stressor-based Prediction................................................... 10

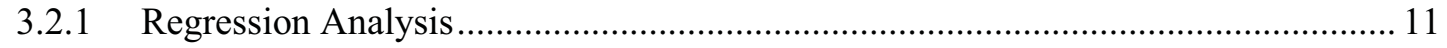

3.3 Type-III Prognostic Models: Degradation-based Prediction............................................. 15

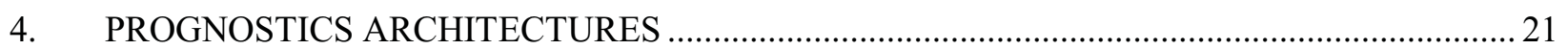

$4.1 \quad$ Applicable Standards, Specifications and Formats ........................................................... 21

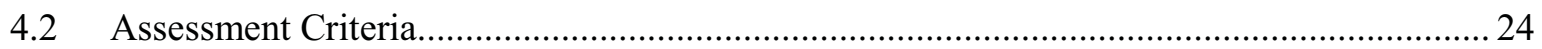

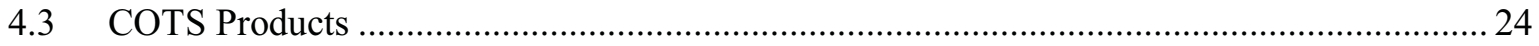

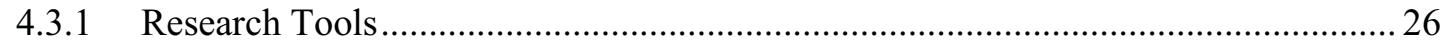

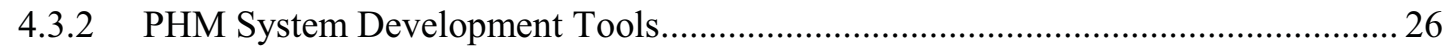

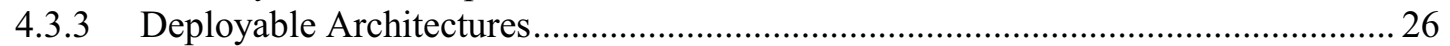

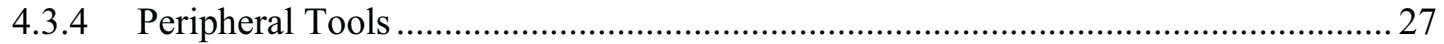

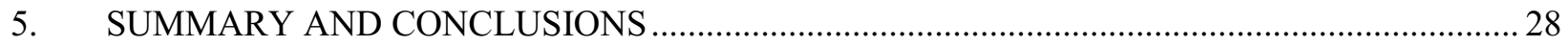

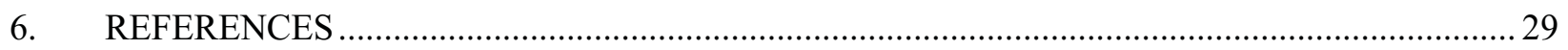

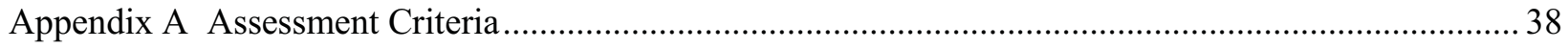

Appendix B Survey of Industries Focusing on Maintenance............................................................... 53

\section{FIGURES}

Figure 1. System, Structure, and Component (SSC) component performance monitoring system

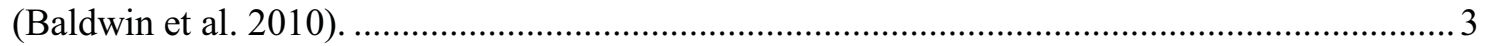

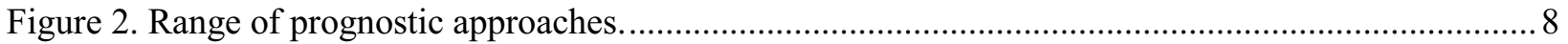


Figure 3. Prognostic algorithm categorization (Hines and Usynin 2008) .......................................... 8

Figure 4. Use of prognostic monitor failure times to estimate RUL of actual circuit

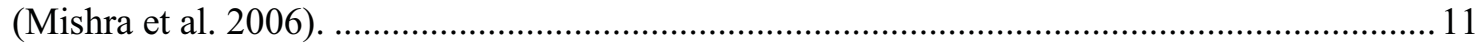

Figure 5. A typical progression of the environmental conditions...................................................... 12

Figure 6. A collection of possible degradation measures. .................................................................. 13

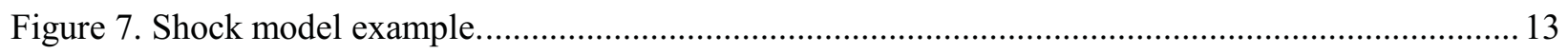

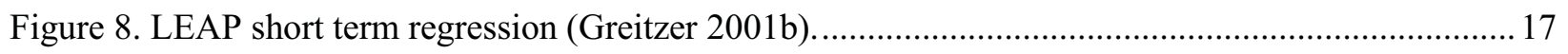

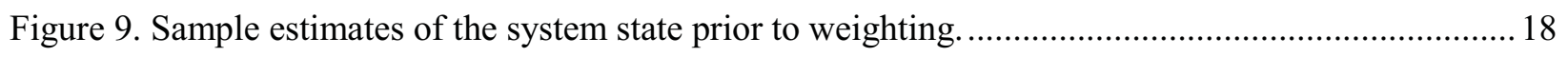

Figure 10. Sample estimates of the system state after weighting.......................................................... 19

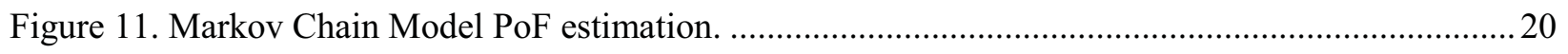

Figure 12. Six functional blocks in a condition monitoring system (ISO 2007). ..................................22

Figure 13. Major functions of OSA-EAI (reproduced courtesy of www.mimosa.org). ..........................2 23

Figure A-1. Integration of the PEM and PEP toolboxes................................................................... 47

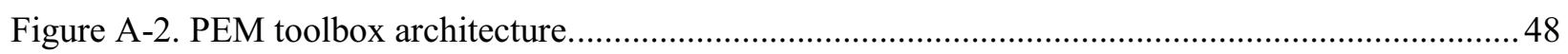

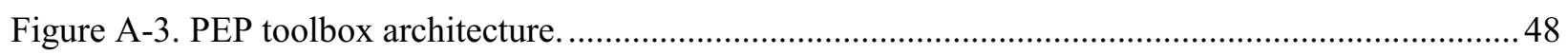

Figure A-4. NPP failure modes detected by SmartSignal (2011)....................................................... 49

Figure A-5. SureSense architecture (expert microsystems) ............................................................... 52

\section{TABLES}

Table 1. State of Maturity for Diagnostics (D) and Prognostic (P) Technologies (Howard (2005)............ 6

Table 2. Features of commercially available integrated health management frameworks. ...................... 25

Table A-1. Watchdog Agent ${ }^{\circledR}$ Toolbox algorithms (IMS 2011).......................................................... 43

Table B-1. Survey of industries focusing on maintenance (from Kothamasu et al. [2006])......................55 


\section{ACRONYMS}

$\begin{array}{ll}\text { AAKR } & \text { Auto Associative Kernel Regression } \\ \text { AANN } & \text { Auto Associative Neural Networks } \\ \text { AG } & \text { Advisory Generation } \\ \text { AOC } & \text { Asset Optimization Centre } \\ \text { AR } & \text { Autoregressive } \\ \text { ARMA } & \text { Autoregressive Moving Average } \\ \text { BBN } & \text { Bayesian Belief Network } \\ \text { BIST } & \text { Built-in Self Test } \\ \text { CBM } & \text { Condition-Based Maintenance } \\ \text { CE } & \text { Central Edition } \\ \text { COTS } & \text { Commercial Off-The-Shelf } \\ \text { CV } & \text { Confidence Value } \\ \text { DA } & \text { Data Acquisition } \\ \text { DCS } & \text { Distributed Control System } \\ \text { DGA } & \text { Dissolved Gas Analysis } \\ \text { DiagML } & \text { Diagnostic Markup Language } \\ \text { DM } & \text { Data Manipulation } \\ \text { EAM } & \text { Enterprise Asset Management } \\ \text { EHM } & \text { Equipment Health Management } \\ \text { EM } & \text { Expert Microsystems } \\ \text { EPRI } & \text { Electric Power Research Institute } \\ \text { ERP } & \text { Enterprise Resource Planning } \\ \text { ESRG } & \text { Engineering Software Reliability Group } \\ \text { FAMOS } & \text { Fleet Asset Management and Optimization Solutions } \\ \text { FMECA } & \text { Failure Modes, Effects, and Criticality Analysis } \\ \text { GMM } & \text { Gaussian Mixture Modeling } \\ \text { GPM } & \text { General Path Model } \\ \text { GUI } & \text { Graphical User Interface } \\ \text { HA } & \text { Health Assessment } \\ \text { HMI } & \text { Human-Machine Interface } \\ \text { HMarkov Model } \\ \text { Hidion and Control }\end{array}$


IAEA International Atomic Energy Agency

IMS Impact Maintenance Scheduler

ISO International Standards Organization

JSF Joint Strike Fighter

KPI Key Performance Indicator

LCM Life Consumption Model

LEAP Life Extension Analysis and Prognostics

LRU Line Replaceable Unit

LTO Long Term Operation

LWRS Light Water Reactor Sustainability

MADe Maintenance Aware Design environment

MAS Multi-Agent System

MIMOSA Machinery Information Management Open Standard Alliance

MRL Mean Residual Life

MSET Multivariate State Estimation Technique

MTTF Mean Time to Failure

NDE Non-destructive Examination

NPP Nuclear Power Plant

O\&M operations and maintenance

OLM Online Monitoring

OSA-CBM Open Systems Architecture for Condition Based Maintenance

OSA-EAI Open Systems Architecture for Enterprise Application Integration

PA Prognostic Assessment

PBMS Prescription Based Maintenance Management System

PCA Principal Component Analysis

PE Plant Edition

PEM Process and Equipment Monitoring

PEP Process and Equipment Prognostics

PH Proportional Hazards

PHM Prognostics and Health Management

POF Probability of Failure

PRA Probabilistic Risk Assessment

PROaCT Prognostics and Reliability Optimization and Control Technologies

RAM Reliability, Availability, and Maintainability

RUL Remaining Useful Life 
SCADA Supervisory Control and Data Acquisition

SD State Detection

SHM Structural Health Monitoring

SIR Sequential Importance Resampling

SIS Sequential Importance Sampling

SPRT Sequential Probability Ratio Test

SSC Systems, Structures, and Components

SVM Support Vector Machine

ToF Time of Failure

UAV Unmanned Aerial Vehicle

UML Unified Modeling Language

$\mathrm{V} \& \mathrm{~V} \quad$ Verification and Validation

XML Extensible Markup Language 


\section{ACKNOWLEDGMENTS}

The authors acknowledge the contributions made in developing this report by Mr. Richard Rusaw (EPRI), Professor Wesley Hines (University of Tennessee), Professor Carol Smidts (The Ohio State University), Dr. Jeremy Busby (ORNL) and Mr. Randy Bickford (Expert Microsystems, Inc). In addition thanks and acknowledgement is given to the various vendors who provided details of the products that are discussed in this report. 


\section{Lifecycle Prognostics Architecture for Selected High-Cost Active Components}

\section{INTRODUCTION}

At the start of 2011, there were 439 nuclear power plants (NPPs) in the commercial global fleet; these plants started operation with 30- or 40-year licenses. In the United States there are 104 plants, and to meet the demand for electricity with an aging fleet there is a growing interest in longer term operation (LTO) of these valuable resources. As of July 2011, nine plants in the U.S. had moved into extended operation (past 40 years); license extensions to operate from 40 to 60 years have been granted for 71 plants at 40 sites. An additional 13 plants at nine sites are currently undergoing review for license extension operate to 60 years, and 16 more are expected to apply for extensions in the next 6 years (US NRC 2011). Many other countries are also considering an additional 10 or 20 years of operation for their plants, and, in the U.S., a second 20 years of license extension (from 60 to 80 years) for the current NPP fleet is being considered. In the light of the accident at Fukushima Nuclear Plant, there are also some countries that have announced that they will phase out nuclear power.

The safe, secure, and reliable operation of aging NPPs presents many challenges. There have been various meetings discussing the issues, including a 2009 Light Water Reactor Sustainability (LWRS) Workshop, which identified OLM of active and structural components as essential to the better understanding of the challenges posed by aging NPPs (Hallbert et al. 2009). Operators of aging NPPs need information on the condition of structures, systems, and components to better manage power-plant life holistically, adjusting operating conditions to reduce the impact of stressors that cause degradation. In managing systems in plants there is increasing adoption of condition-based maintenance (CBM) for active components. Such techniques provide a foundation upon which a variety of advanced online surveillance, diagnostic, and prognostic techniques to continuously monitor and assess the health of NPP systems and components can be deployed.

Active components are managed under a maintenance rule. The use of OLM for fault detection and diagnosis in a condition-based approach identifies components that need to be replaced or repaired based on condition rather than age. Current practice uses signatures and pattern recognition to identify anomalies and off-normal conditions. Moving beyond identification of "faults" is development of fault degradation models and prognostic methods that provided estimates of remaining useful life. The deployment of prognostic methods allows for use of more proactive Prognostic Health Management (PHM), where components are opportunistically repaired or replaced based on the estimated time of failure. The aerospace and defense communities have demonstrated that PHM can bring significant advantages in terms of availability, enhanced safety, and reduced fleet operation costs (Vachtesvanos et al. 2006; Larsen et al. 2004). CBM is being deployed in nuclear plants and implementation of these proactive prognostic technologies in NPPs is expected to benefit the quest to maintain high capacity factor, shorten planned outages (currently about 40 days), maintain safety, and facilitate life extension in existing plants.

Implementation of PHM in existing NPPs poses many challenges, and to be accepted must initially be demonstrated with deployment of a minimum of additional sensing capabilities. The Electric Power Research Institute (EPRI) has already demonstrated the feasibility of OLM at several participating U.S. NPPs, including Harris, Limerick, Salem, Sequoyah, Three Mile Island, and V. C. Summer (EPRI 2003; Hines and Seibert 2006). Additionally, OLM has been implemented in Europe, both at British Sizewell B and Electricité de France nuclear facilities (Hines and Seibert 2006). There are already known to be significant opportunities to deploy new technologies when upgrades, including modernization of instrumentation and control systems, are implemented at existing facilities. The economic benefit from a 
predictive maintenance program can be demonstrated from a cost/benefit analysis. An example is the program for the Palo Verde Nuclear Generating Station (Johnson and Maxwell 2002). An analysis of the 104 U.S. legacy systems has indicated that monitoring and diagnostics has the potential for savings at over \$1B per year when applied to all key equipment (Bond et al. 2008).

The availability of low-cost wireless sensor technologies makes the broad deployment of PHM across the U.S. nuclear industry more feasible, enabling rapid deployment of multiple sensors for condition monitoring. There has been research work that established feasibility of its use in pump monitoring, where wired and wireless data were collected on the same systems (Jarrell et al. 2004). To date, wireless sensor technologies have been implemented in a few U.S. NPPs, including Limerick, San Onofre, and Comanche Peak (Korsah et al. 2009; IAEA 2008). In addition there has been work to demonstrate the technology with rotating equipment in research reactors (Hashemian 2011a).

Current state of the art for OLM in NPPs includes leak monitoring and systems that measure reactor noise, acoustic signals, and vibration in various forms (IAEA 2011a). Measurements of several reactor environmental parameters (temperature, pressure, neutron flux), also occur online (IAEA 2011b). In addition there are some aspects of sensor calibration that are addressed OLM (Hashemian 2011b; IAEA 2011a). When the state of the art is reviewed (Bond 2010; ASME 2010) it appears that many, if not all, active components (pumps, valves, motors, etc.) in an NPP can potentially be well managed, routinely diagnosed, analyzed, and upgraded as needed using a combination of periodic and online CBM. However, opportunities exist to both centralize monitoring and employ more advanced and predictive or prognostic technologies, which can reduce operation and maintenance costs, and potentially maintain high capacity factor, as plants enter extended operation. The use of more automated and OLM and analysis also has the advantage of potentially being better using limited staff resources and reducing worker dose.

As attention turns to longer term operation, interest is increasing in understanding the fundamental degradation signatures for both active and passive components and how these relate to the underlying degradation phenomena. The ability to successfully manage the passive systems and structures in NPP is seen as critical to the goal of long-term operability (Bond et al. 2011; Bond and Meyer 2011). These passive components can also benefit from the deployment of prognostic methods that utilize many of the same algorithms as those used with active components.

This report reviews the state of the art and discusses alternate approaches and methodologies in three areas that are at the core of the application of prognostics to components in an NPP. The first is the choice of components and systems to be monitored (discussed in Section 2). The second is the various classes and types of prognostic algorithms (see Section 3). The third is an initial assessment of the various prognostics architectures that are being considered for, or have been applied to, problems relevant to deployment in NPP (see Section 4). A summary and some conclusions are given in Section 5. An Appendix A, "Assessment Criteria," provides some additional details for some commercial off-the-shelf (COTS) architectures. 


\section{COMPONENT SELECTION METHODOLOGY}

The primary objectives of PHM systems are to detect abnormal conditions, determine root causes of faults, assess the degree of damage, and estimate remaining useful life (RUL), where the RUL is defined to be the time until the performance is no longer expected to meet either a specification or a minimal requirement, with an acceptable level of confidence or probability of failure (POF).

In looking at the process of OLM, there is a series of elements in the process that can be identified. This hierarchy of responses, culminating in mitigation actions, is illustrated in Figure 1. The overarching goal of implementing PHM systems in NPPs is to improve the safety, reliability, and economics/profitability of the aging nuclear fleet and extend their service life in the most cost-effective manner.

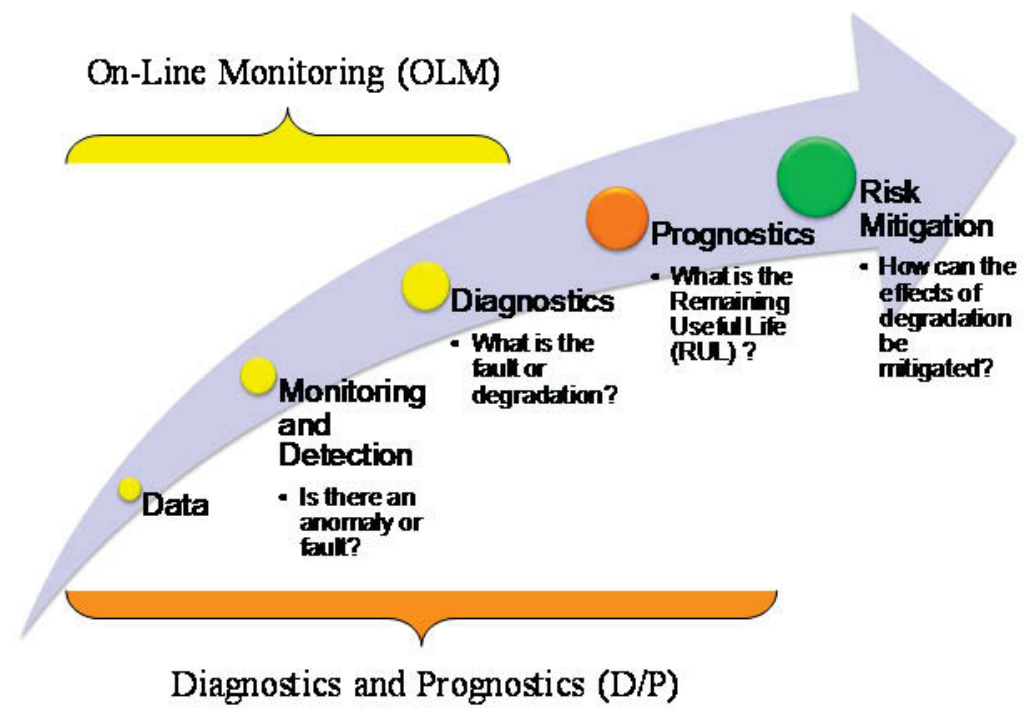

Figure 1. System, Structure, and Component (SSC) component performance monitoring system (Baldwin et al. 2010).

Selection of the components and structures to be monitored is a crucial step for successful PHM implementation in NPPs. The system selection process includes selection of both the component (active and passive) and the appropriate monitoring approach to be deployed. As in any decision-making process, this selection should be based on rigorous consideration of the numerous parameters that are identified as significant influencing factors. These factors include the feasibility of a specific monitoring procedure, component failure probability, risk (or consequences) associated with component failure, and the overall benefits of the implemented monitoring system. The initial decision process should be designed to handle both known and potential new phenomena associated specifically with aging components in extended operation beyond initial design period in NPPs.

There are also economic factors, both as they relate to a specific plant, and research and development costs associated with addressing needed science and technology. Such funding issues and investment discussions, although important, are outside the scope of this report.

The following have been identified as the primary factors that affect the selection of SSC for monitoring: feasibility of deployment, failure probability, consequences of failure, and benefits of monitoring. Each of these factors is discussed briefly in the following subsections. 


\subsection{Feasibility}

In assessing feasibility there are a series of individual topics that require consideration:

- Timeline. The PHM system implementation should meet the timeline requirements of the aging fleet of existing NPPs by providing monitoring capabilities before major structures and components fail.

- Operational compatibility with other components. The additional system should not pose an unacceptable increase in risk, in terms of its impact on other components (instrumentation constraints). Typically, the number of installed sensors available is small in NPPs. The sensors are still considered the potential "weak link" because they are on occasion less reliable than the systems they monitor. Advanced sensor validation and qualification is required to overcome this sensor reliability issues. More challenges come from the harsh environments that can be encountered in some parts of the NPP system.

- Availability of operational data, including failure data. Empirical (data-driven) techniques are constructed from operational data (including historical time to failure data) and use signal processing and transformation techniques to extract information-rich features for input into a variety of models such as neural networks, nonlinear regression algorithms, and Markov Chains to diagnose faults and predict the RUL. These methods require access to large quantities of data from failures observed in the field. Statistical data for the performance of many common systems in other industries, such as motors and pumps, are available in various data bases (Cornell et al. 1982; Mighdoll et al. 1982; MRWG 1985a; MRWG 1986b; Hale and Arno 2001a; 2002b). More limited data are available that provide signatures of systems as performance degrades, particularly those in nuclear plants.

- Availability of physics-based failure models or reliable component failure data. Model-based (physics-of-failure) approaches use mathematical models of the degradation mechanisms. These methods also consider environmental stresses (e.g., temperature, load, vibration, etc.) on the component. They estimate the life for an average component under the given usage conditions. These techniques require reliable physical models of phenomena occurring not only in the monitored component, but across the entire plant. Alternatively, accurate failure data can be used to derive empirical models that describe failure progression. High value systems are rarely allowed to run to failure once degradation has been detected; however, well-designed accelerated test data may be used with appropriate transformations.

- Verification and validation $(\mathbf{V} \& \mathbf{V})$. Adequate $V \& V$ of prediction models or procedures including uncertainty quantification is necessary to mitigate false alarms, missed alarms, and inaccurate RUL predictions. The hardware and software complexity poses hurdles for any V\&V process, particularly when quantifying the risk of incorrect prediction. Novel ways to provide automated V\&V are needed and have been deployed in the defense and aerospace industries. Where components (e.g., pumps and motors) are also deployed in other industries, common approaches can be utilized; however, there are some unique needs faced by the aging NPPs that may require nuclear-specific approaches.

- Actionable decisions. Predictions should provide actionable information, and the methodologies must give the user a high degree of confidence. This is particularly so when decisions can impact safety, the confidence of the component condition assessment, the availability of resources to mitigate the problem, the cost to the operator, and the ability to reschedule the planned maintenance.

\subsection{Component Failure Probability}

Calculation of failure probability requires understanding the physics of failure, state awareness, fault and failure progression rates, performance properties as components age, and the effects of degradation across the systems. Failure probabilities for some components are included in probabilistic risk assessment (PRA), which is also being expanded to include the effects of aging. EPRI has a preventive 
maintenance application center that gathers data on components, as well as provides recommended maintenance programs for more than 130 component types. However, the failure probabilities of at least some less common and high value components in NPPs are potentially poorly quantified.

\subsection{Consequences Associated with Component Failure}

Many consequence scenarios and their occurrence probability associated with the component failure are quantified in PRA analysis. Such analysis is commonly extended to formally include plant downtime, equipment repair and replacement cost, possible exposure to personnel and the environment; and is used to support the business case for preventative maintenance and CBM (e.g., Johnson and Maxwell; 2002a,b).

\subsection{Benefits of the PHM System}

The deployment of PHM systems in the defense and aerospace community has demonstrated that such systems provide significant benefits, which include:

- Safety benefits - Reduce risk, minimize safety impact, and increase reliability.

- Operational benefits - Avoid unplanned plant shutdown, decrease focus on reliable systems or components, and increase flexibility in scheduling of maintenance. This leads to improved planning of inspection and repair activity, higher quality maintenance, shorter and less complex outages, fewer "surprises" during outages, elimination of unnecessary tests, and reduced radiation exposure.

- Financial benefits - Increase plant availability and capacity factor by avoiding unplanned plant shutdown and using optimal maintenance schedules.

Ultimately, the overall clear benefits of the PHM system will be the decisive factor in the selection process. After target components have been selected, development of a viable PHM system depends on selection of appropriate model algorithms. The following chapter briefly overviews prognostic algorithms and their areas of applicability. 


\section{PROGNOSTIC ALGORITHMS}

Prognostics is the prediction of a future condition, the effect of degradation on a system's capability to perform its desired function, and remaining safe or service life, based on an analysis of system or material condition, stressors, and degradation phenomena. This prediction can be made using various classes of algorithms. Moving from diagnostics, which gives an assessment at a point in time based on observed data (e.g., an non-destructive examination NDE or structural health monitoring (SHM)assessment), to prediction of life and technologies for structural health monitoring/management based on predicted future behavior can be achieved using the range of classes of approaches that are identified in schematic form in Figure A-1. These range from the general statistical databased assessments, based on populations, such as the performance of all pumps of a particular type or class to those based on physical degradation models with specific data taken on a particular part or component. Those methods shown at the top of the pyramid increase accuracy, but they also come at a higher cost, require greater understanding of the system under study, and also commonly more data for analysis.

An assessment of the state of the art in diagnostics and prognostics in terms of technology maturity for different classes of system was provided by Howard (2005). The status for these various elements is shown in Table 1. Since that time, the technology has continued to develop, and it has been reported at various technical meetings. Technologies are being developed for non-nuclear applications, including instrumentation and system health monitoring for electronics, in what is being called "electronics prognostics" (Urmanov 2007). There are also integrated technologies being developed for advanced fighter aircraft and unmanned aerial vehicle (UAV) system health monitoring, which include both electrical/electronic and mechanical systems. A review of machinery diagnostics and prognostics for CBM is provided by Jardine et al. (2006), but again it does not consider nuclear power systems. There is also a review by Kothamasu et al. (2006) that considered both the current health monitoring paradigms and the tools and standards. The results of their survey of industries focused on maintenance are given as Appendix B.

Table 1. State of Maturity for Diagnostics (D) and Prognostic (P) Technologies (Howard (2005).

\begin{tabular}{lcccc}
\hline \multicolumn{1}{c}{ Diagnostic/Prognostic Technology for: } & $\mathrm{AP}^{(\mathrm{a})}$ & $\mathrm{A}^{(\mathrm{b})}$ & $\mathrm{I}^{(\mathrm{c})}$ & $\mathrm{NO}^{(\mathrm{d})}$ \\
\hline Basic Machinery (motors, pumps, generators, etc.) & $\mathrm{D}$ & & $\mathrm{P}$ \\
Complex Machinery (helicopter gearboxes, etc.) & & $\mathrm{D}$ & $\mathrm{P}$ \\
Metal Structures (passive and active) & $\mathrm{D}$ & & $\mathrm{P}$ \\
Composite Structures (passive and active) & & $\mathrm{D} \& \mathrm{P}$ \\
Electronic Power Supplies (low power) & $\mathrm{D}$ & $\mathrm{P}$ \\
Avionics and Controls Electronics & & $\mathrm{P}$ & \\
Medium Power Electronics (radar, etc.) & $\mathrm{D}$ & & $\mathrm{P}$ \\
High Power Electronics (electric propulsion, etc.) & & & $\mathrm{D} \& \mathrm{P}$ \\
\hline (a) AP $=$ Technology currently available and proven effective. & & & \\
(b) A = Technology currently available, but V\&V not completed. & & & \\
(c) I $=$ Technology in process, but not completely ready for verification and validation. & & \\
(d) NO $=$ No significant technology development in place. & & & \\
\hline
\end{tabular}

Monitoring technologies developed in other industries can potentially benefit NPPs, particularly when using advanced OLM and diagnostics for CBM, and prognostics in the future. Digital instrumentation and control (I\&C) and advanced diagnostics and prognostics are being developed in the wider hightechnology industry communities and are now also being considered for NPP deployment. 
The prognostics research that is reported in the literature largely focuses on solutions to specific problems, such as electronic prognostics (Vichare and Pecht 2006; Ridgetop Group 2004; Mishra and Pecht 2002; Kalgren et al. 2007), vibration analysis (Carden and Fanning 2004; Doebling et al. 1996; Catbas and Atkan 2002), helicopter gearbox monitoring (Engel et al. 2000; Heng et al. 2009; Vachtsevanos et al. 1997; Wang and Vachtsevanos 2001; Orchard and Vachtsevanos 2007; Kacprzynski et al. 2004), Joint Strike Fighter (JSF) applications (Keller et al. 2006; Orsagh et al. 2005; Roemer et al. 2005; Ferrell et al. 1999; Ferrell et al. 2000; Smith et al. 1997; Hess and Fila 2002; Line and Clements 2005), etc. There are now papers in several major meeting series including the Machinery Failure Prevention Society annual meeting, the IEEE Reliability Society meetings, the PHM Society annual conference, and sessions within application-specific meetings, such as those for aerospace systems. The landscape has developed further through activities such as those of the NASA Prognostics Center and a number of reliability groups. While research has resulted in good point solutions for these specific problems, generic prognostic algorithms, which may be more broadly applicable across a variety of systems, are still less mature. The goal of current work by several groups is to provide generic prognostic algorithms, which may be rapidly configured for a new system to allow for effective and efficient deployment of CBM and PHM technology on large, complex systems (Baruah et al. 2006).

In reviewing the range of models, as already indicated, prognostic algorithms can be classified as ranging from physics-based to statistical and this full range of prognostic models is shown in Figure 2.

Physics-based models, also called physics-of-failure models or first-principles models, are potentially the most accurate, and most focused on a particular application, but can be expensive to develop. Often, at the start of a project the underlying physical processes leading to failure are not completely understood, and simplifying assumptions must be made to facilitate more rapid model development. Such models can be computationally expensive, particularly if Monte Carlo simulations are used to estimate confidence intervals about model predictions, although the increasing availability of computer power makes this less of an issue.

Alternatively, empirical models use data to fit a model to the relationships seen in real world operation and degradation. These models typically provide no additional information about the physical mechanisms leading to failure. Empirical models can, in some cases, be preferable to physics-of-failure models because they are simpler to develop, they capture real world relationships, and they require little or no expertise in the underlying physical phenomena that cause failure. However, empirical models have several drawbacks. These models rely on operational data for model development. As such, the models are generally only applicable to systems operating within the range of the training data used in model development. This poses additional problems for prognostics models, which rely on run-to-failure data for model training. Very few expensive or safety critical systems are allowed to run to failure, particularly in the nuclear power industry; in this case, high fidelity physics-of-failure simulations may be used to generate failure data for model development. Additionally, data collected in accelerated life tests may provide useful information for prognostic model development. This data requires additional processing to correlate accelerated results to those expected in real world application (Elsayed and Chen 1998; Carey and Koenig 1991; Lemoine and Wenocor 1985; Tang and Chang 1995; Park and Padgett 2006). 


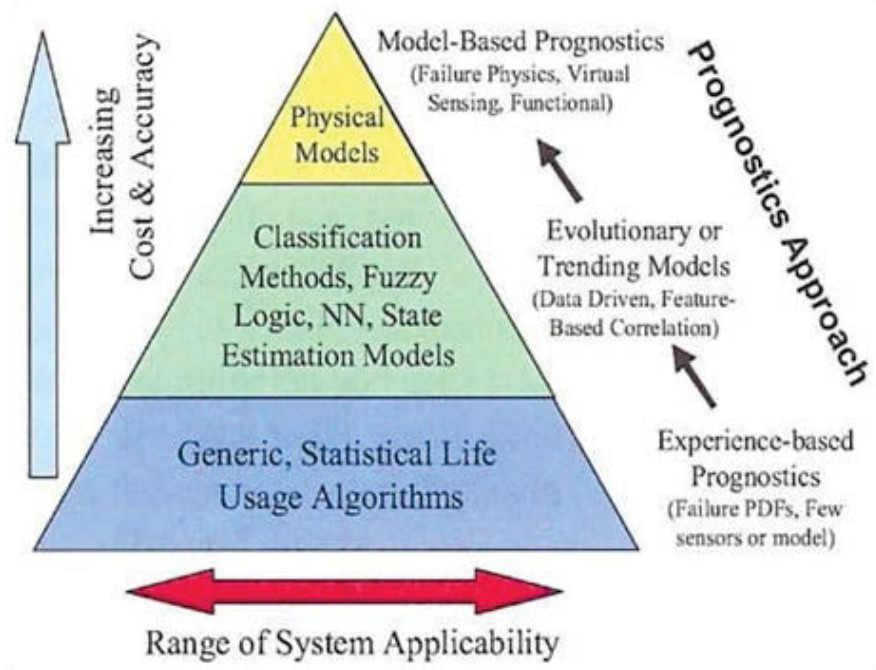

Figure 2. Range of prognostic approaches.

As suggested by the "No Free Lunch" Theorem, no one prognostic algorithm is ideal for every situation (Ho and Pepyne 2002; Koppen 2004). A variety of models have been developed for application to specific situations or specific classes of systems. The efficacy of these algorithms for a new process or system depends on the type and quality of data available, the assumptions inherent in the algorithm, and the assumptions that can validly be made about the system. As such, these prognostic algorithms can be categorized according to many criteria. One proposed categorization focuses on the type of information used to make prognostic estimates; this results in three classes of prognostic algorithms (Figure 3) (Hines and Usynin 2008).

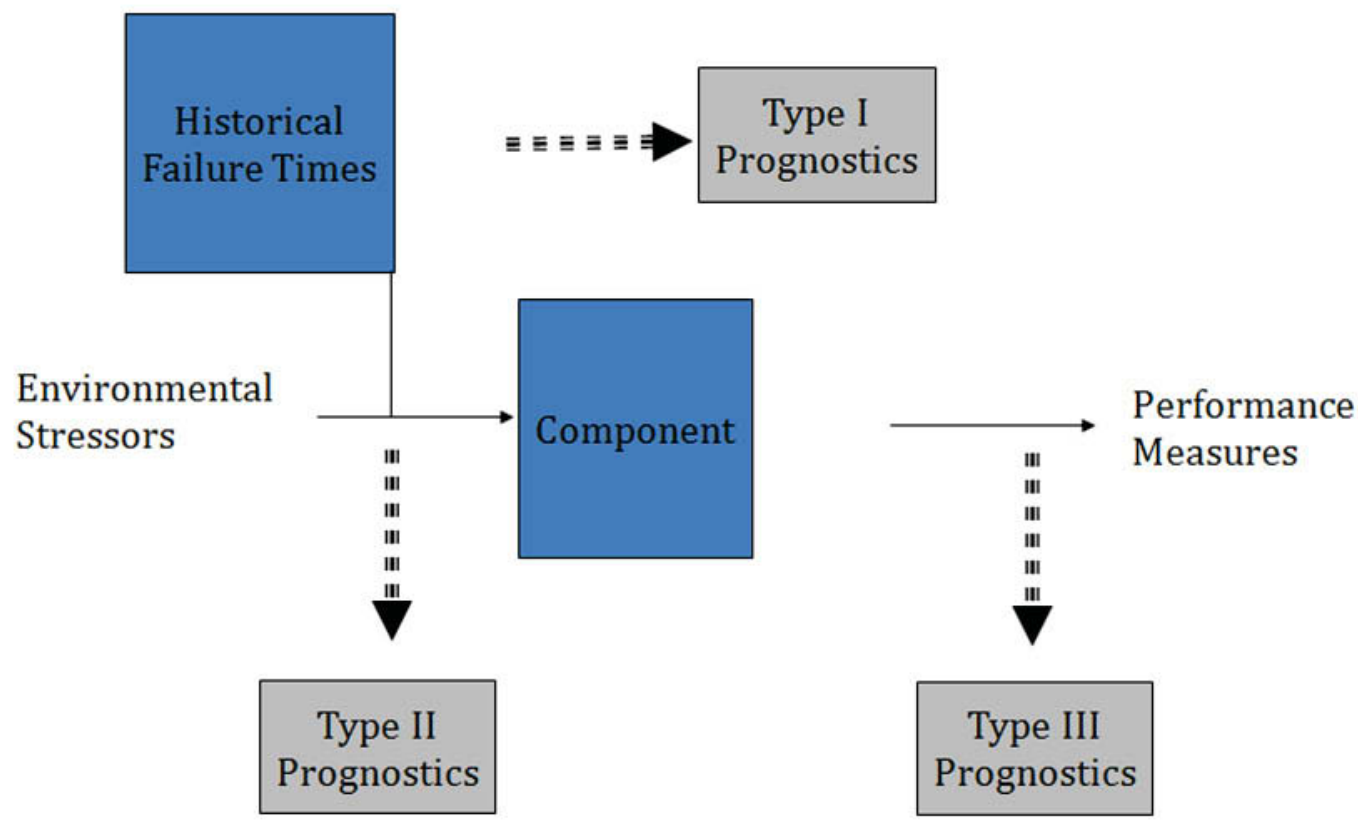

Figure 3. Prognostic algorithm categorization (Hines and Usynin 2008). 
Type-I, or reliability-based, prognostics is traditional time-to-failure analysis; this type of prognostic algorithm characterizes the expected lifetime of an average system operating in a historically average environment. These methods may be applied if no data specific to the current system is available. Examples of Type-I prognostics include Weibull analysis, exponential or normal distribution analysis, and nonparametric distribution analysis. A readily apparent shortcoming of this group of methods is the absence of consideration for operating conditions and environment in making RUL estimates. Typically, systems operating in harsher conditions will fail more quickly while those in milder environments more slowly.

Type-II, or stressor-based, prognostics use operational and environmental condition data to estimate RUL. This type of prognostics characterizes the lifetime of an average system or component operating in a specific environment. Type-II methods can be used if operating conditions, such as load, input current and voltage, ambient temperature, vibration, etc., are measurable and correlated to system degradation. Algorithms in this class include simple regression analysis, specific formulations of the Markov Chain model and shock model, the proportional hazards model, and the life consumption model. Although more specific than Type-I models, Type-II models are deficient because they neglect unit-to-unit variance that may be due to variability in manufacturing, installation, and maintenance actions.

Type-III, or degradation-based, prognostics characterize the lifetime of a specific unit or system operating in its specific environment. Extrapolation of a general path model (GPM) or a particle filter model is the most common empirical Type-III method. This extrapolation involves trending a prognostic parameter and extrapolating it to some predefined failure threshold. A prognostic parameter is a measure that is either directly sensed from the system or inferred from a set of sensor readings that characterizes system degradation or health. System failure is commonly indicated by a soft failure threshold at which the system no longer performs to its specifications or cannot be expected to perform for an appreciable amount of time; this is generally some point before a catastrophic failure occurs. Additional Type-III methods include degradation-based formulations of the Markov Chain model and the shock model. This kind of individual-based analysis is generally considered the ultimate goal of prognostics for safety-critical or high-value components and systems.

Each of these classes of prognostic algorithms, as well as appropriate modeling methods, is discussed in greater detail in the following sections.

\subsection{Type-I Prognostic Models: Traditional Time-to-Failure Analysis}

Type-I methods are a simple extension of traditional reliability analysis, based entirely on a prioritized distribution of failure times for similar systems in the past. Prognostic algorithms in this class characterize the average lifetime of an average system operating in historically average conditions; they do not utilize any information specific to the system at hand. The main assumptions made when applying Type-I methods are that future systems will operate under similar conditions to those seen in the past and will fail in similar ways.

Type-I prognostic models are built on a population of historical failure data, including both failed and censored units. A probability distribution is fit to these runtimes to give an estimate of the time of failure (ToF) distribution of the population. The most common parametric model used in reliability analysis is the Weibull distribution. This model is used because it is flexible enough to model a variety of failure rates. The formula for the failure rate is a two parameter model with a shape parameter $(\beta)$ and a characteristic life $(\theta)$ :

$$
\lambda(t)=\frac{\beta}{\theta}\left(\frac{t}{\theta}\right)^{\beta-1}
$$


These two parameters provide the modeling flexibility for components exhibiting an increasing failure rate $(\beta>1)$, a constant failure rate $(\beta=1)$, and a decreasing failure rate $(\beta<1)$. With the correct choice of shape parameter, the Weibull distribution adequately models the exponential, normal, or Rayleigh distributions. Additional information on Weibull modeling is available in Abernethy's handbook (1996).

Traditional reliability methods consider only the total runtime of a system and the historic total lifetimes of similar systems. However, several methods are available to include additional information in reliability analysis, which may make it more useful for prognostics. Yang and Xue (1996) suggest a method for analyzing both catastrophic and soft failures simultaneously using random process simulation and state tree analysis.

Several studies suggest the use of degradation data in estimating reliability distributions. Lu and Meeker (1993) first proposed the GPM, which shifts reliability analysis from failure time to failure mode analysis. Improvements to their seminal work are proposed by Girish et al. (2003) who used neural networks to estimate the failure times for censored systems; Kharoufeh and Cox (2005) apply Markovian degradation models to estimate the failure time for censored systems; Chen and Zhang (2005) attempt to infer the lifetime distribution itself instead of the distribution parameters from the available data; and Xu and Zhao (2005) extend the approach to use multivariate degradation measures.

As a new unit is operated, the ToF distribution can be used, along with the total runtime of the new unit, to estimate the RUL. Most commonly, the Mean Residual Life (MRL) is used to estimate the remaining lifetime, given that a system has run for its current lifetime. For a unit of age $t$, the MRL method assumes that the remaining life is a random variable, and the MRL is given by the expected value of this random variable (Guess and Proschan 1985):

$$
M R L(t)=\frac{1}{S(t)} \int_{t}^{o} S(u) d u
$$

where $S(\cdot)$ is the survival function and $t$ is the current time. The MRL at time $t$ can be calculated from either parametric or nonparametric distributions, which makes it particularly flexible for application to real world data.

Studies applying Type-I prognostics to estimation of RUL have shown the method to be unsatisfactory (Pecht et al. 2002; Lall et al. 1997). This is to be expected since the MRL method assumes that the remaining life is a random variable; clearly it is not. In fact, because mean residual life is an "average" measure, it is expected to underestimate RUL about half the time and overestimate RUL about half the time. Vichare et al. (2004) show that Type-I methods are insufficient for electronic prognostics; the authors go on to suggest that in situ monitoring of operating conditions, such as temperature, humidity, vibration, and shock, may improve prognostic model performance. This leads to Type-II prognostic methods.

\subsection{Type-II Prognostic Models: Stressor-based Prediction}

As suggested by the journal articles by Vichare et al. (2004), Azzam (1997), and Baybutt et al. (2009), it is intuitive to consider usage conditions, both past and future, when estimating the RUL of a system. Type-II methods attempt to do this by characterizing the lifetime of an average component operating in the specific environment. Here, it is assumed that systems operating in the same conditions will fail in similar ways; there is little unit-to-unit variance. Methods that commonly fall into this category include regression analysis, a specific formulation of the Markov Chain model, Proportional Hazards Models, physics-of-failure models, and Life Consumption models. Studies utilizing each of these architectures are described below. 


\subsubsection{Regression Analysis}

Electronic system prognostics on the board or circuit level commonly utilize a built-in self test (BIST) prognostic monitor or canary (Goodman 2000; Hofmeister et al. 2006a; Hofmeister et al. 2006b; Mishra et al. 2006). A prognostic monitor is a "pre-calibrated semiconductor cell that is collocated with the actual circuit on a semi-conductor device" (Mishra et al. 2006). The prognostic cell is designed to experience a higher current level than the actual circuit by decreasing the cross sectional area of the current-carrying path in the canary. Because the canary cell undergoes a higher current density, it is expected to fail in a predictably faster way than the actual circuit. By colocating several prognostic monitors on a circuit with different known accelerating factors, the failure times of each of the cells can be trended to predict failure in the actual circuit (Figure 4). While this method is convenient and uncomplicated, Pecht et al. (2001) argue that BIST monitors are not always sufficient for detecting and identifying failures. The authors found BIST results to suffer from a high false alarm rate and a low correlation between the fault indicated by the BIST and the actual fault. These shortcomings should be considered before applying this type of prognostic monitoring module.

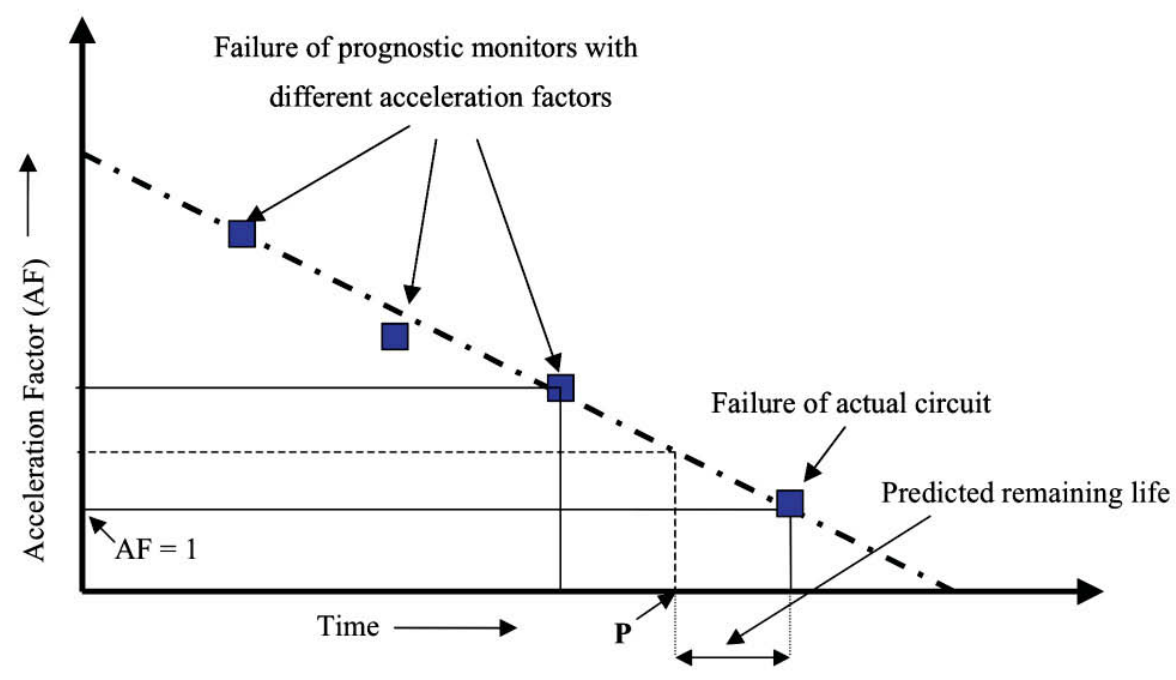

Figure 4. Use of prognostic monitor failure times to estimate RUL of actual circuit (Mishra et al. 2006).

\subsubsection{Markov Chain Models}

Markov Chains and Hidden Markov Chains are common in many simulation exercises (Bogdanoff and Kozin 1985). The Markov Chain model is based on the assumption that the next state that a system will occupy depends only on the current state; past states do not affect the probability of transitioning to the next state. There are two types of Markov Chain prognostic models, which vary only in the information they use to simulate possible future states. Type-II Markov Chain models, described here, really include two models.

The first model, called the environmental model, is a Markov Chain simulation that produces possible future operating state progressions based on transition probabilities seen in the past and the current operating state. The environment model predicts how the environment and operating conditions evolve in the future. The environmental model is defined by the transition probability matrix: 


$$
Q=\left[\begin{array}{ccc}
p_{11} & \cdots & p_{1 n} \\
\vdots & \ddots & \vdots \\
p_{n 1} & \cdots & p_{n n}
\end{array}\right]
$$

where $p_{i j}$ is the probability of transitioning from state $i$ to state $j$. Often this probability matrix is assumed to be static, but it is straightforward to extend the method to time-dependent or degradation level-dependent transition probabilities, leading to Type-III formulations. The environmental model is used to simulate many possible future state progressions beginning at the current state.

These state progressions are then mapped to a degradation measure, which is the second model necessary in the Type-II Markov Chain algorithm. The degradation measure is a function of observable environmental conditions. To be useful for making a reliability prediction, the function should reflect the manner in which the environmental conditions affect the component reliability. Usually, environmental stressors tend to deteriorate the component reliability in a cumulative manner. Hence, the function to relate the environment conditions to the prognostic parameter is commonly a cumulative form:

$$
Y\left(t_{k}\right)=\sum_{i=1}^{k} g\left(E\left(t_{i}, t_{i}+\Delta t_{i}\right)\right) \Delta t_{i}
$$

where $Y\left(t_{k}\right)$ is the degradation measure value at time $t_{k}, E\left(t_{i}, t_{i}+\Delta t_{i}\right)$ is the environmental condition observed at the time interval $\left[t_{i}, t_{i}+\Delta t_{i}\right]$, and $g($.) is an appropriate function of environmental conditions.

When the estimated degradation measure crosses some predefined threshold, the unit is considered failed. At each time of interest, many possible state progressions are simulated and mapped to degradation measures. These measures are then used to define a ToF distribution for the system. Figure 5 shows a typical progression of the environmental conditions in time. An example of trajectories is given in Figure 6 in which the function $g($.$) is assumed to be an identity function.$

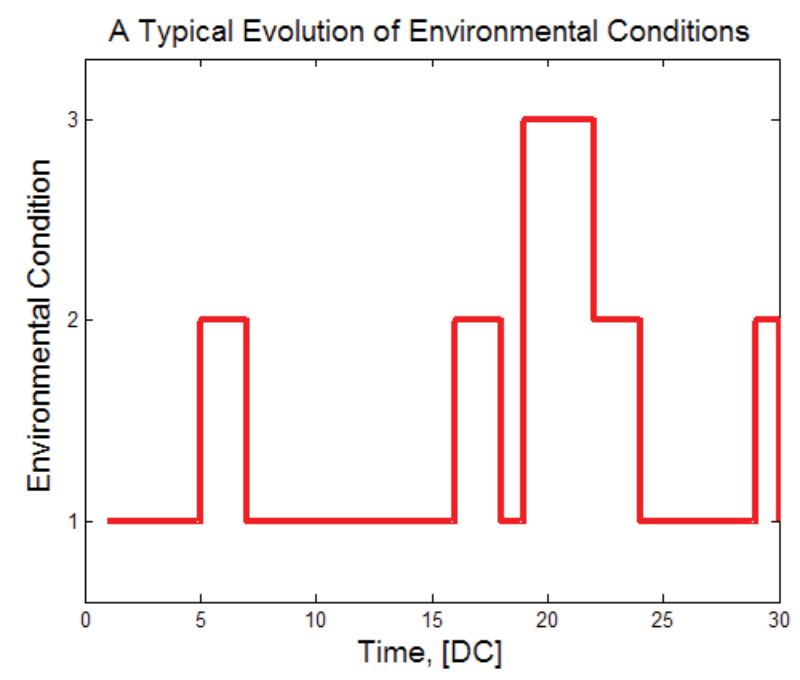

Figure 5. A typical progression of the environmental conditions. 


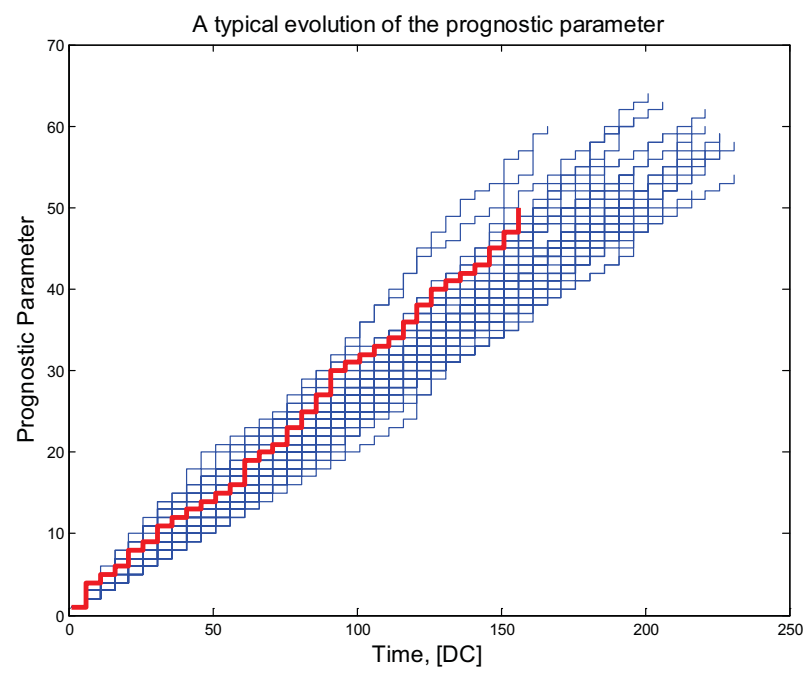

Figure 6. A collection of possible degradation measures.

\subsubsection{Shock Models}

The Markov Chain model is continuous in the time domain, but discrete in the degradation measure; that is, a specified amount of degradation is associated with each state. A more general formulation is the Shock model (Esary and Marshall 1973; Gut 1990; Mallor and Santos 2003). Instead of experiencing some known amount of degradation, or shock, in each state, the shock model allows for a shock of random size. Shock models have three parameters that are estimated from historical data: time between successive shocks, $t \sim \operatorname{Exp}(l)$, magnitude of the shocks, $x \sim F(x)$, and the critical failure threshold. An example of the shock model is shown in Figure 7., where the time between shocks and the shock size are both random variables.

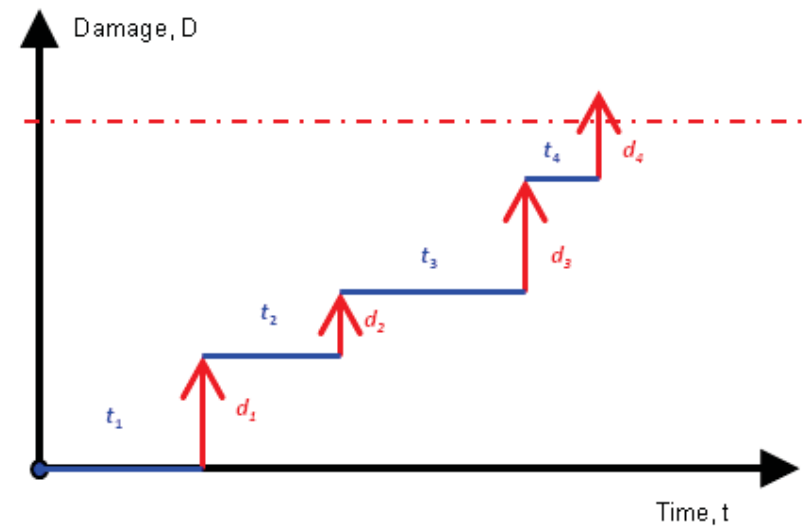

Figure 7. Shock model example.

In this model, the time between random shocks is a continuous random variable, with the probability of shock often determined by the system runtime, operating conditions, current degradation state, or some combination thereof. The size of the shock may be based on a single shock size distribution, or other features such as the current degradation measure, operating condition, or other measures available from the system and environment. Again, when the cumulative degradation measure crosses some 
predetermined threshold, the system is considered failed; a probability of failure distribution is estimated from multiple simulated degradation measures.

\subsubsection{Proportional Hazards Models}

The Proportional Hazards (PH) Model developed by Cox and Oakes (1984) merges failure time data and stress data to make RUL estimates. The model uses operating conditions, called covariates, to modify the baseline hazard rate to give a new hazard rate for the system's specific usage conditions:

$$
\lambda(t ; z)=\lambda_{0}(t) \exp \left(\sum_{j=1}^{q} \beta_{j} z_{j}\right)
$$

Failure data collected at covariate operating conditions are used to solve for the parameters $\left(\beta_{j}\right)$ using an ordinary least squares algorithm. The baseline hazard is the hazard rate when covariates have little or no influence on the failure rate. A basic assumption of the proportional hazards model is that the effects of these covariates are multiplicative; this means that when the ratio of two covariates is evaluated, their hazard rates are proportional. A full discussion of developing a proportional hazards model can be found in Kumar and Klefjo's article (1994). Dale (1985) applied the proportional hazard model to estimation of product reliability, applying it to heterogeneous data from non-repairable systems. Liao et al. (2006) suggest the use of proportional hazards models for estimating RUL, though the authors give no specific results of such an application.

\subsubsection{Physics-of-Failure Models}

Physics-of-failure models, or first-principles models, are often desirable in engineering applications because they provide a greater understanding of the mechanisms by which systems and components may fail. Physics-of-failure models are also desirable for high-cost, high-risk systems that cannot be run to failure many times to collect the data needed for development of empirical models (Pecht and Dasgupta 1995; Jarrell et al. 2004). The use of physics-of-failure models for estimating RUL has focused mainly on electronic system prognostics (Oja et al. 2007; Valentin et al. 2003). These models may be readily available for single components or single fault modes; however, developing accurate physics-of-failure models for large, complex systems is a daunting task. Physics-of-failure models often suffer from inaccuracies due to the assumptions made in developing the model, the exclusion of physical interactions which are not completely understood, and long runtimes. Kacprzynski et al. (2002) attempt to alleviate the inaccuracies of physics-of-failure models by fusing the results with other data sources such as diagnostic results, prognostics architectures, inspection information, and real-time system level features. The authors applied their system to a gear with a seeded fault and found very promising results for the data fusion technique. In Kacprzynski et al.'s article (2004), the same methodology was applied to helicopter gearboxes with similar success. Physics-of-failure models offer a better understanding of the mechanisms of failure for a component or system, but they are costly and tedious to develop for large, complex systems which experience many fault modes. In addition, the run time needed for many damage propagation models may make them impractical for real-time analysis. For systems with accurate physics-of-failure models available, it may be prudent to use these models to simulate system failure data. That simulated data may then be used to develop empirical models which may be run very quickly. This alleviates the burden of collecting failure data for expensive or safety critical systems. Physics-of-failure models are a key component of Life Consumption Models (LCMs).

\subsubsection{Life Consumption Models}

Life Consumption Models were first proposed by Ramakrishnan and Pecht (2003) for monitoring RUL in electronic systems. The LCM methodology monitors the environment of a component or system 
during its entire lifecycle to determine the amount of damage incurred through the various loads and conditions experienced. This damage is translated to lost "life," which is subtracted from the expected life of an average system or component. The incurred damage is estimated through physics-of-failure models; this damage amount is related to a fraction of life lost by considering the total amount of operation under the same conditions, which would result in failure of an undamaged part. LCM is illustrated in Ramakrishnan and Pecht (2003) and Mishra et al.'s (2004) papers by application to a mounted printed circuit board operated under the hood of a moving vehicle. Both temperature and vibration levels were monitored on the board during use. The methodology was shown to effectively estimate RUL of the circuit board, even in the event of unexpected damage accumulation caused by a large, random shock. The major drawback of the LCM methodology is the need for accurate physics-of-failure models to estimate the accumulated damage. As mentioned above, physics-of-failure models are often not available, not accurate, or not time-effective for large, complex systems. Development of a more general LCM methodology which utilizes empirical models, such as neural networks, kernel regression models, or simple regression, for damage estimation would increase the applicability of this algorithm.

\subsection{Type-III Prognostic Models: Degradation-based Prediction}

Finally, the last category of prognostic algorithms attempts to characterize the lifetime of the specific system operating in its specific environment. These Type-III prognostic methods are termed degradation-based or condition-based. The most common method in this class is extrapolation of a parametric model. This can be accomplished through a GPM or a particle filtering model. Basically, these methods attempt to track some measure related to degradation, also called a prognostic parameter, and extrapolate it to failure. The prognostic parameter may be something measured directly from the system that gives information about system condition and fault severity, or it may be inferred from measurements made on the system. Additional algorithms included in Type-III prognostics are a different formulation of Markov Chain models and shock models.

Each of the Type-III prognostic algorithms involves the use a prognostic parameter to monitor and trend degradation in an individual component. The following section introduces the idea of the prognostic parameter. This is followed by discussion of several key Type-III algorithms.

\subsubsection{Prognostic Parameter}

A prognostic parameter, also called a degradation measure, is a scalar or vector quantity that numerically reflects the current ability of the system to perform its designated functions properly. It is a quantity that is correlated with the probability of failure at a given moment. A degradation path is a trajectory along which the degradation measure is evolving in time towards the critical level corresponding to a failure event. Type-III prognostics attempt to extrapolate along this degradation path to determine the RUL of a component or system.

The degradation measure does not have to be a directly measured parameter. It could be a function of several measured variables that provide a quantitative measure of degradation. It could also be an empirical model prediction of the degradation that cannot be measured. For example, pipe wall thickness may be an appropriate degradation parameter, but there may not be an unobtrusive method to directly measure it. However, there may be related measurable variables that can be used to predict the wall thickness. In this case the degradation parameter is not a directly measurable parameter but a function of several measurable parameters. Monitoring system residuals are intuitive candidates for prognostic parameters because they naturally characterize how "far" a system is from normal operation.

When the degradation level of a system reaches some predefined critical failure threshold, the system is said to have experienced a soft failure; for example, car tire tread is below some specified depth. These failures generally do not concur with complete loss of functionality, as in a hard failure; however, they 
correspond with the time when an operator is no longer confident that equipment will continue to work to its specifications. Both general path models and particle filters attempt to extrapolate the prognostic parameter to a critical failure threshold to estimate the RUL; these algorithms are described in the following sections.

\subsubsection{General Path Model}

The GPM was first proposed by Lu and Meeker (1993) to move reliability analysis from failure time to failure mode analysis. The first work to extend their methodology to prognostics was by Upadhyaya et al. (1994). The authors in that work apply traditional regression models and neural networks to trend system degradation. In later years, the extrapolation methodology of traditional regression models was applied to helicopter gearboxes (Engel et al. 2000), flight control actuators (Byington et al. 2004), aircraft power systems (Keller et al. 2006), computer power supplies (Hines et al. 2006), global positioning systems (Brown et al. 2007), and lithium-ion batteries (Liu et al. 2010). In addition, work by Chinnam (1999) applied the GPM methodology to feed forward neural networks for estimating degradation levels. Each of these studies attempts to model a degradation measure and extrapolate it to some predefined threshold to estimate the system RUL. Only a few of the studies consider the problem of uncertainty measurements. These studies tend to take two approaches to uncertainty estimation. Uncertainty measurements in (Engel et al. 2000) and (Hines et al. 2006) are estimated based on the model architecture used to make the prediction, while Byington et al. (2004) utilized Bayesian belief models to estimate the uncertainty. Liu et al. (2010) utilized a bootstrap approach wherein the prognostic model is developed and executed many (in this work, 50) times and features of the RUL prediction are estimated from the aggregate results.

Key to development of a GPM prognostic model is development of the degradation model. Studies to date have primarily focused on linear regression models (Coble 2010; Hines et al. 2006) and neural networks (Liu et al. 2010). If accurate physics-of-failure models are available, these may be used to trend the system degradation. In these models, the physics-of-failure model utilizes measurements directly from the system of interest to estimate the hidden damage (Luo et al. 2003). Here, the authors utilized a residual monitoring system to estimate the hidden damage in a system; this basic methodology can be applied to physics-of-failure models or empirical models. As in the previous discussion, Type-III physicsof-failure models suffer from difficulty in development, inaccuracies due to the assumptions made in model development, and long runtimes. However, if accurate physics-of-failure models are available, they can be applied to prognostic algorithms and used with the GPM methodology.

Greitzer et al. (1999; 2001a; 2001b) propose a slightly different formulation of the GPM, called the Life Extension Analysis and Prognostics (LEAP) method. LEAP differs from GPM primarily in that it is a short-term regression model. Instead of regressing a model onto the entire operating history of a system or component, LEAP utilizes some recent window of data for the regression. Although using more data tends to lead to more stable predictions, using the entire operating history may mask recent changes in behavior that are of critical importance. While these predictions have greater variability, they tend to be more sensitive to recent and abrupt changes in condition, as seen in Figure 8. The LEAP methodology is proposed as a Type-II method using operating conditions to estimate some figure of merit and then trending that figure of merit to failure. However, the extension to Type-III prognostics is clear, where the figure of merit is directly measured or inferred from direct measurements of the system. This methodology is an improvement on the traditional GPM in that it is more sensitive to abrupt changes; however, it is also less robust to noisy measurements. Identification of an optimal window size for regression is a critical task in applying this technique. 


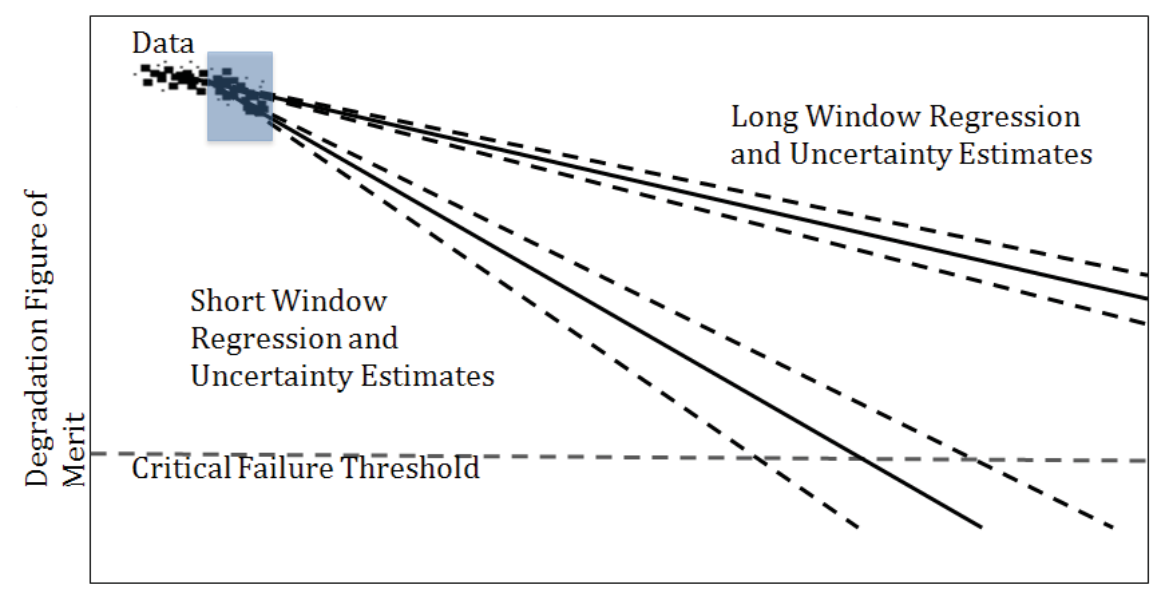

Independent Variables (e.g. Time)

Figure 8. LEAP short term regression (Greitzer 2001b).

\subsubsection{Particle Filters}

Particle filtering was originally developed to provide an estimation of the marginal probability in Bayes' Theorem that would allow for modeling of nonlinear systems and potentially non-Gaussian noise (Cadini 2009). The particle filter method utilizes Monte Carlo simulation to provide an approximate solution to the marginal distribution by generating artificial random samples and comparing their distribution to that of the measurements. The particle filter method first starts with Bayes' Theorem:

$p\left(\boldsymbol{x}_{k} \mid \mathbf{z}_{0: k}\right)=\frac{p\left(\boldsymbol{z}_{k} \mid \boldsymbol{x}_{k}\right) * p\left(\boldsymbol{x}_{k} \mid \mathbf{z}_{0: k-1}\right)}{p\left(\mathbf{z}_{k} \mid \mathbf{z}_{0: k-1}\right)}$.

Here, $\mathbf{x}$ represents the state-space vector of the system, which is not directly measured. In condition monitoring, this is typically the prognostic parameter or other measure of system health. The term $\mathbf{z}$ represents the vector of measurements. Measurements are first taken at time $=0$; the "current" time, or the time of interest is represented by the subscript $k$, and the previous time step is $k-1$. The term $p\left(\boldsymbol{x}_{k} \mid \boldsymbol{z}_{0: k}\right)$ is defined as the posterior distribution and represents the distribution of the likelihood of a system state $\mathbf{x}_{\mathrm{k}}$ existing given the measurements $\mathbf{z}_{0: \mathrm{k}}$ (i.e., all measurements, including the current measurement). The term $p\left(\boldsymbol{z}_{k} \mid \boldsymbol{x}_{k}\right)$ is the conditional probability and represents the likelihood that a given state would yield the current measurements. The term $p\left(\boldsymbol{x}_{k} \mid \mathbf{z}_{0: k-1}\right)$ is the prior distribution and is the likelihood that a given state would exist based on all measurements prior to the current measurement. Finally, $p\left(\mathbf{z}_{k} \mid \mathbf{z}_{0: k-1}\right)$ is the marginal probability and represents the likelihood that the current measurements would occur given all previous measurements.

The long-standing difficulty with Bayes' Theorem is determining the marginal probability, and this is the purpose of particle filtering. The first step in particle filtering is Sequential Importance Sampling (SIS), where a known distribution is used to generate random samples for $\mathbf{x}_{0: \mathrm{k}}$. In contrast to GPM, SIS updates all particles (i.e., samples) simultaneously at a given time step rather than updating a single particle all the way to failure. The distribution only needs to ensure that the range of possibilities is covered, though a distribution that closely resembles the true distribution of probabilities should provide faster convergence and more reliable results. This distribution is defined as an importance function:

$q\left(\boldsymbol{x}_{k} \mid \mathbf{z}_{0: k}\right)$. 
Next, weights for the sample particles are defined by relating the importance function to the posterior distribution:

$w_{k}^{i} \propto \frac{p\left(x_{k}^{i} \mid \mathbf{z}_{0: k}\right)}{q\left(x_{k}^{i} \mid \mathbf{z}_{0: k}\right)}$.

In the above equation, both terms in the ratio are unknown. However, the weights from the previous time step are known and can be used to approximate the weights according to Equation 1. The approximation may require normalization to form a true pdf; this can be readily performed after all weights are estimated.

$w_{k}^{i} \propto w_{k-1}^{i} * \frac{p\left(z_{k} \mid x_{k}^{i}\right) p\left(x_{k}^{i} \mid x_{k-1}^{i}\right)}{q\left(x_{k}^{i} \mid x_{0: k-1}^{i}, z_{0: k}\right)}$

A visual example of the weighting process may be seen in Figure 9 and Figure 10. Prior to weighting, all samples have equal weight. At Time Step 20, those particles whose states have a higher likelihood of representing the true state of the system (as estimated through measurements) receive greater weight; the particles with less likelihood of representing the system receive less weight. Having reweighted the particles, they now represent an updated posterior distribution of the marginal probability and the new posterior distribution may be estimated.

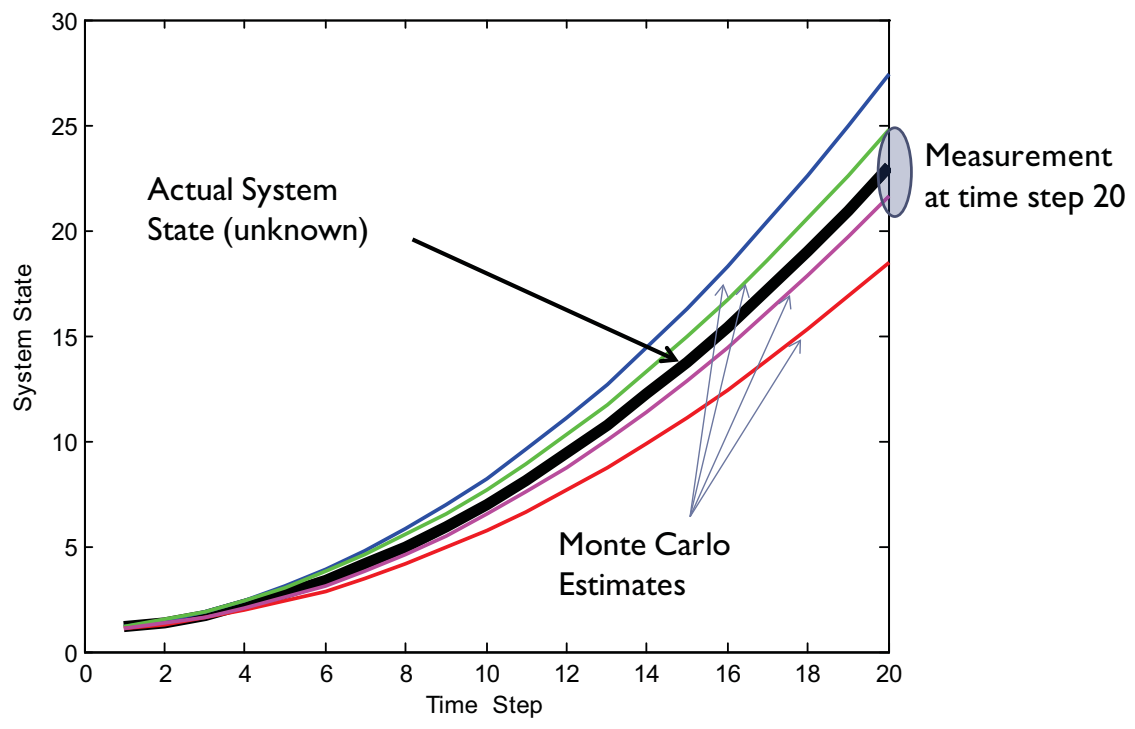

Figure 9. Sample estimates of the system state prior to weighting. 


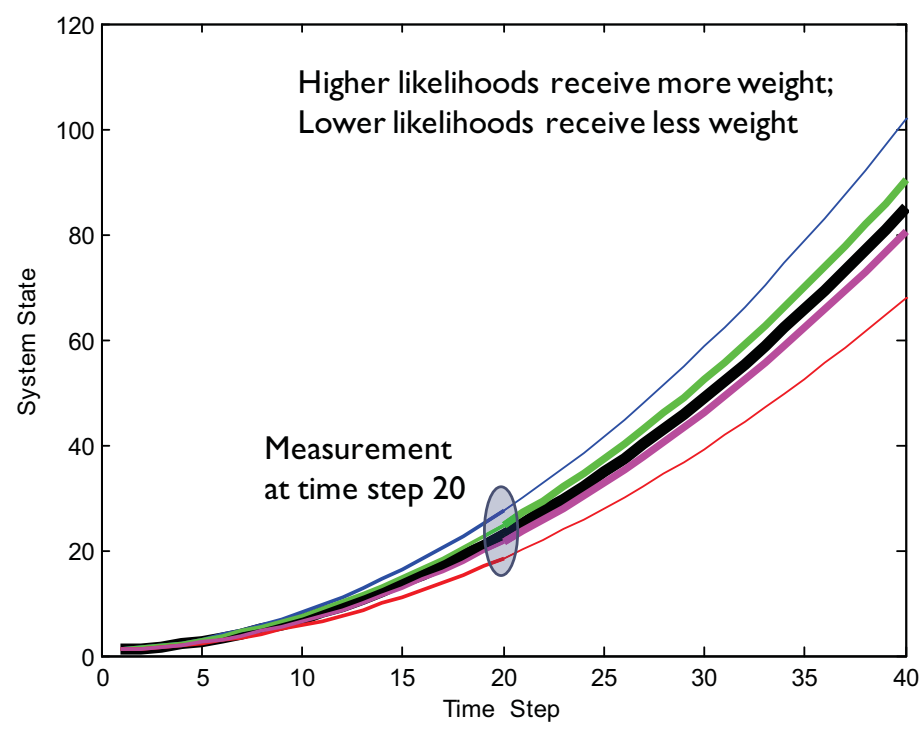

Figure 10. Sample estimates of the system state after weighting.

As this process is repeated, the particle weights are continually updated every time Bayes' Rule is applied. Since SIS will add weight to particles with the highest likelihood at the expense of lower-likelihood particles, the process will eventually drive the weights of all particles to zero except for the highest-likelihood particle, a problem known as degeneracy. To avoid degeneracy, the particles are occasionally redistributed by Sequential Importance Resampling (SIR).

SIR may be conducted by a variety of methods, but the general approach is to replace the existing weighted particles with new unweighted particles chosen by the posterior distribution provided by SIS. In review, SIS may be seen as a filter of particle weights where the weights are updated to fit the estimated posterior distribution. Therefore, SIR may be seen as a filter of the particles themselves, where new particles are chosen based on the weighted particles after SIS. This two-stage process is the heart of particle filtering.

Because particle filtering employs a Monte Carlo process, uncertainty estimates may be readily provided by the existing particle distributions. The state estimate at the present time is given by Equation 2. The failure probability estimate at a future time $k+i$ is given by Equation 3. Finally, the failure time distribution at a future time $k+i$ is given by Equation 4 .

$p\left(\boldsymbol{x}_{k} \mid \mathbf{z}_{0: k}\right) \approx \sum_{i=1}^{N} w_{k}^{i} \delta\left(\boldsymbol{x}_{0: k}-\boldsymbol{x}_{0: k}^{i}\right)$

$\hat{p}(k+i) \approx \frac{\sum_{m, x_{k}^{m}>d^{*}} w_{k}^{m}}{\sum_{n, x_{k}^{n}>d^{*}} w_{k}^{n}}$

$p\left(\tau_{k} \mid \mathbf{z}_{0: k}\right) \approx \sum_{i=1}^{N} w_{k}^{i} \delta\left(\tau_{k}-t^{i}\right)$

Additional statistical inferences may be made via the particle distributions, such as $95 \%$ confidence intervals, hypothesis tests, etc.

\subsubsection{Markov Chain and Shock Models}

As mentioned previously, Markov Chain models can fall into the Type-II or Type-III category. While Type-II Markov Chain models use the Markov assumption to generate possible future operating condition 
progressions, Type-III Markov Chain models use the Markov assumption to generate random shock arrival times based on the current degradation level (Hines and Usynin 2008; Hines et al. 2007; He et al. 2006). These random shocks contribute some deterministic amount of degradation, usually one unit, to the degradation measure. The time of failure is calculated as the time when this simulated degradation measure crosses the failure threshold. At each time of interest, many degradation paths are simulated, and a Mean Time to Failure (MTTF) distribution is estimated from the collection, as shown in Figure 11. The Markov Chain model is continuous in the time domain, but discrete in the degradation measure.

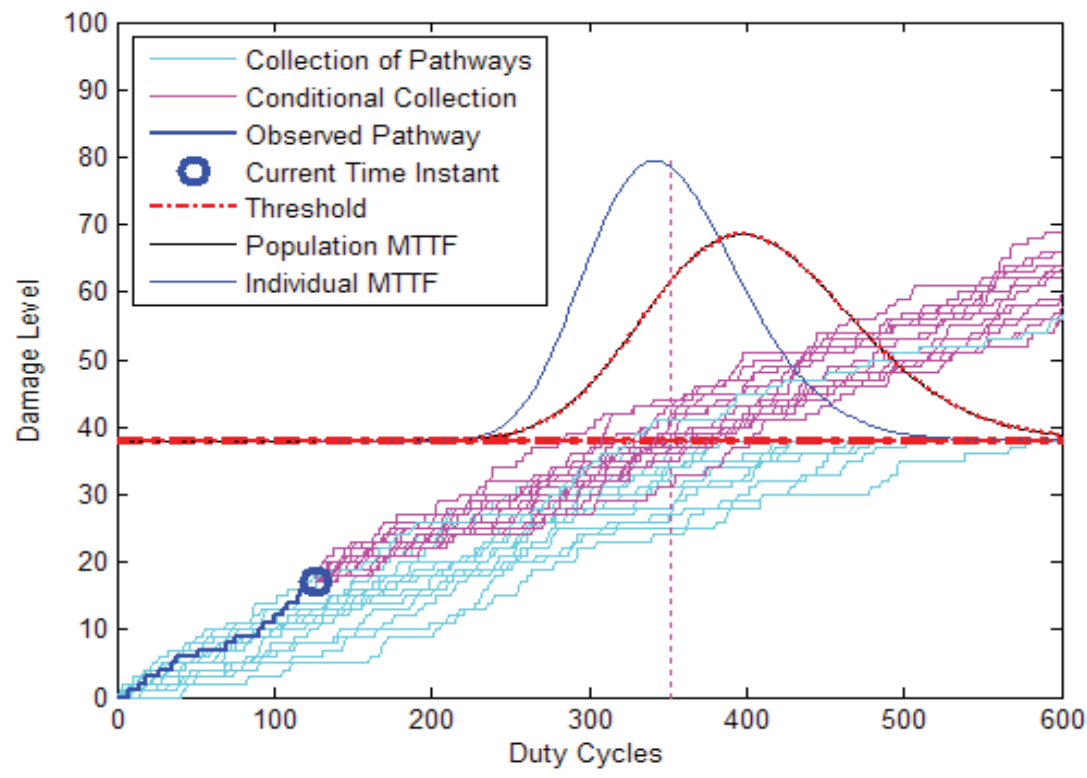

Figure 11. Markov Chain Model PoF estimation.

Similarly, the Type-III formulation of the shock model uses the current level of system degradation, either directly measured or inferred, to generate the time of arrival and/or the magnitude of random shocks to the system. This model is continuous in both time and shock size. When the projected cumulative degradation resulting from random shocks crosses some predefined threshold, the system is considered failed. Monte Carlo techniques make estimation of RUL uncertainty or a full RUL distribution straightforward. 


\section{PROGNOSTICS ARCHITECTURES}

Implementation of PHM on a system or subsystem of any scale within an NPP will require the use of a prognostics architecture (i.e., a software product [or suite of products] used to bring together and implement the necessary pieces for a complete implementation of PHM). This broad definition includes condition monitoring and diagnostics in addition to prognostics; hence, a more appropriate terminology would be an integrated health management framework.

Careful evaluation of available products is necessary to avoid use of limited or stovepipe applications and ensure long-term success of the prognostics implementation. There have been many reviews of prognostic methodologies and algorithms available in the literature, including a recent review by Peng, Dong, and Zuo (2010). In 2006, Hines and Seibert (2006) identified software systems being used for sensor calibration in NPPs; however, there appears to have been no publically available comprehensive assessments of commercially available integrated health management frameworks for the nuclear industry. This section seeks to provide an initial assessment.

\subsection{Applicable Standards, Specifications and Formats}

Technical standards and specifications are used to create a common framework within a chosen field or application, including establishing common terminology, communications protocols, and functionalities. The use of standards promotes interoperability and minimizes redesign of similar systems (Sheppard et al. 2008).

The following standards, specifications, and formats have been identified as being related to prognostics: International Standards Organization (ISO) 13374, ISO 13381, ISO 18435, SAE AIR5871, Machinery Information Management Open Standards Alliance (MIMOSA) Open Systems Architecture for Condition-based Maintenance (OSA-CBM), MIMOSA Open Systems Architecture for Enterprise Application Integration (OSA-EAI), and the Diagnostic Markup Language (DiagML).

ISO 13374 is a collection of standards that define a general condition monitoring architecture (framework) for machines. Part 1 (ISO 2003) focuses on general procedures; Part 2 (ISO 2007) focuses on data processing; Part 3 (ISO, unpublished) is in development, and covers communication (ISO 2009). ISO 13374 defines six layers or blocks of functionality within a condition monitoring system, as seen in Figure 12. The functions of the blocks summarized below are discussed in more detail in (Walter 2006).

The first three blocks are typically technology specific (e.g., vibration monitoring, temperature monitoring, electrochemical monitoring) and provide these functions:

- Data Acquisition (DA). Converts an output from the transducer to a digital parameter representing a physical quantity and related information (such as the time, calibration, data quality, and data collector utilized, sensor configuration).

- Data Manipulation (DM). Performs signal analysis, computes meaningful descriptors, and derives virtual sensor readings from the raw measurements.

- State Detection (SD). Facilitates the creation and maintenance of normal baseline "profiles," searches for abnormalities whenever new data are acquired, and determines in which abnormality zone, if any, the data belong (e.g., alert or alarm). 
The second three blocks combine human concepts with monitoring technologies to assess the current health of the machine, predict future failures, and provide recommended action steps to operations and maintenance personnel:

- Health Assessment (HA). Diagnoses any faults and rates the current health of the equipment or process, considering all state information.

- Prognostics Assessment (PA). Determines future health states and failure modes based on the current health assessment and projected usage loads on the equipment and/or process, as well as remaining useful life.

- Advisory Generation (AG). Provides actionable information regarding maintenance or operational changes required to optimize the life of the process and/or equipment.

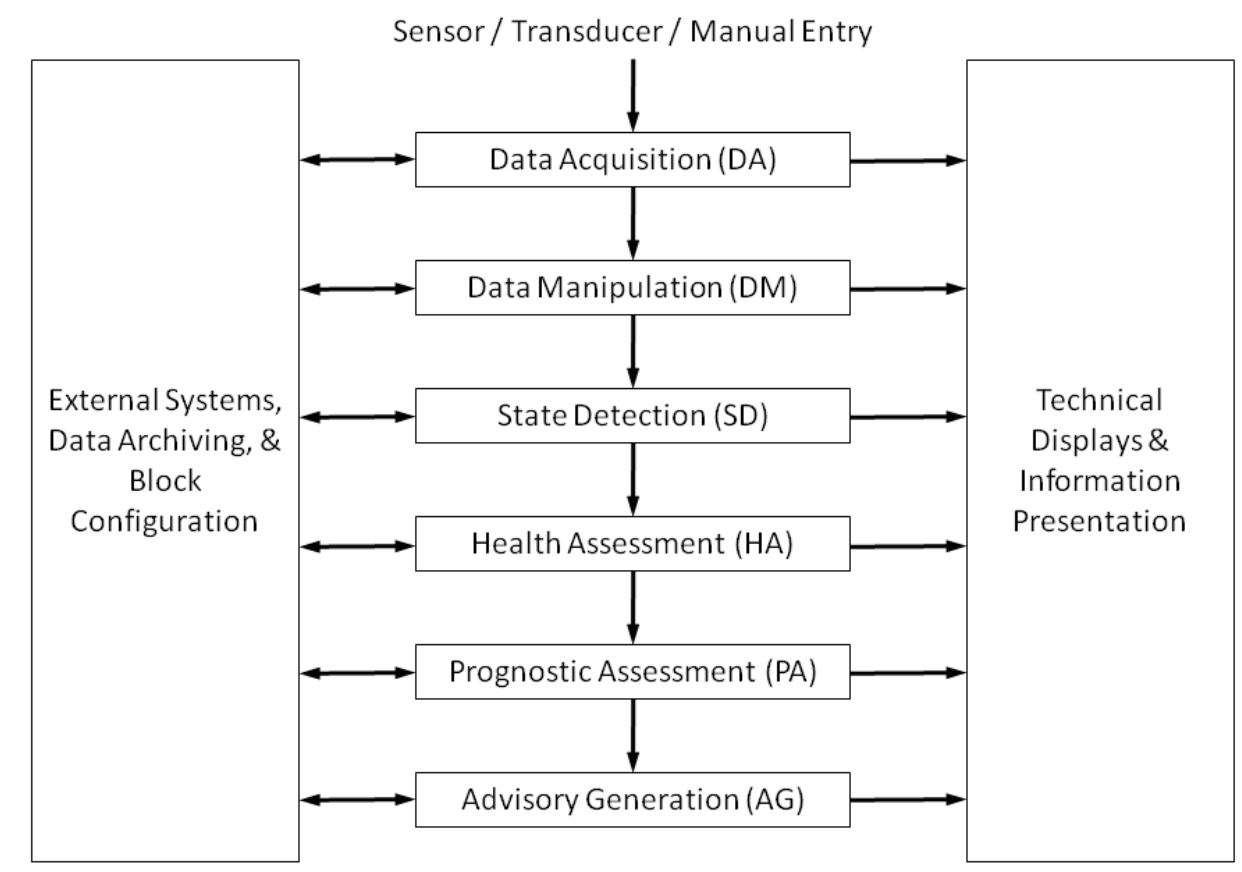

Figure 12. Six functional blocks in a condition monitoring system (ISO 2007).

ISO 13381 (ISO 2004) provides general guidelines for the development of machinery prognostics, addressing terminology, concepts, uncertainty, and degradation modeling (Tobon-Mejia et al. 2010).

ISO 18435 (ISO 2009) describes an integration model and interfaces to facilitate integration of CBMrelated information with operating and environmental information to support optimal decision-making for effective and efficient manufacturing (Carnahan et al. 2005).

SAE AIR5871 (SAE 2008) applies to prognostics of gas turbine engines. The standard defines prognostics terminology, explains potential benefits and limitations of prognostics, provides general guidelines for the use of prognostics using existing condition monitoring systems. Examples are included in this standard.

MIMOSA OSA-CBM is an implementation of the ISO-13374 functional specification (Walter 2006). OSA-CBM uses the Unified Modeling Language (UML) to define the standard, separating the 
information from the technical interfaces used to exchange or communicate the information. This implementation allows vendors and integrators to implement the most appropriate technologies for their application.

MIMOSA OSA-EAI defines a data repository for asset management (MIMOSA 2010). The OSAEAI database includes information about engineering, maintenance, operations, and reliability, as shown in Figure 13.

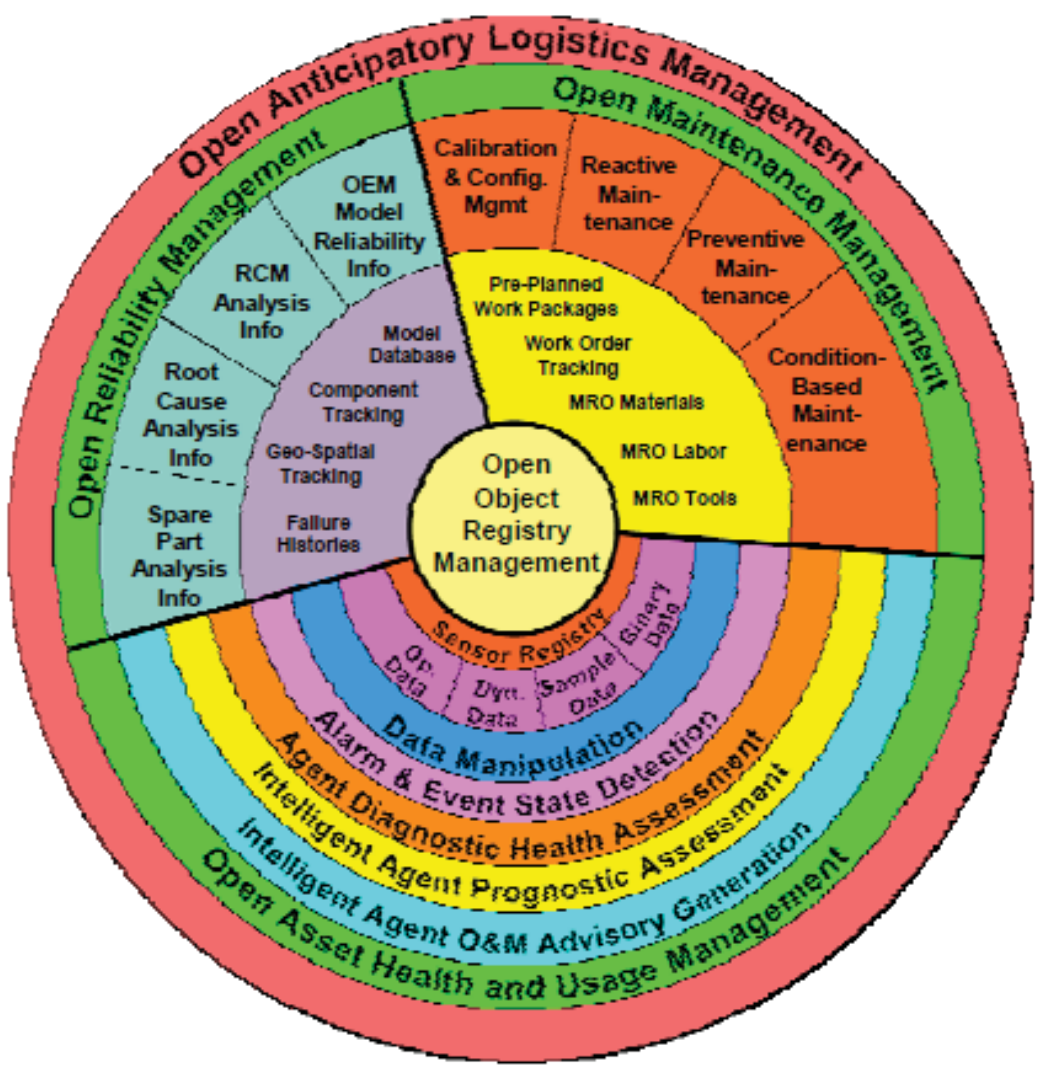

Figure 13. Major functions of OSA-EAI (reproduced courtesy of www.mimosa.org).

DiagML is a fully Extensible Markup Language (XML) schema that defines a format for transferring diagnostic information (Diag-ML 2011). DiagML was produced by DSI International and TYX Corporation. DiagML has been used in a wide variety of commercial applications. Impact Technologies, Boeing, and NASA's Jet Propulsion Laboratory have all developed projects demonstrating the use of DiagML. 


\subsection{Assessment Criteria}

To assess the suitability of commercially available integrated health management frameworks for use in NPPs, a list of desired features has been developed.

1. Open, modular architecture.

The architecture should be independent of the selection of diagnostic or prognostic algorithms, so that a change in desired algorithm can be quickly and easily accomplished. This includes having wellpublished interfaces allowing researchers to create algorithms that will work with the architecture.

2. Platform independence.

The architecture should not be tied to any single computer platform, but rather should be able to operate on as many platforms as possible.

3. Graphical user interface (GUI).

Control room or other site staff could easily be overwhelmed by the amount of data available to them. A well-designed GUI is necessary so that the technician or operations and maintenance professional does not miss critical information.

4. Web-based tool set.

The use of web applications promotes flexibility in the system by allowing ready access to information over a computer network.

5. Scalability.

The product must be scalable to systems that range from the single motor or pump to subsystems within a plant (e.g., those that comprise a service water system) or modules that combine to comprise a full NPP.

6. Compatibility with existing or emerging standards and specifications.

Standards and specifications are used to promote interoperability and minimize redundancy. Existing prognostics standards and specifications are listed in Section 4.1.

\subsection{COTS Products}

For most efficient utilization of funding resources, use of a commercially available integrated health management framework would be ideal. Thirteen candidate products and architectures have been identified based on discussions with experts in the field, review of the literature, and Internet search. Each of these products is briefly described in Appendix A. The relevant features are summarized in Table 2.

The analysis presented is based on information available in product fact sheets and brochures, on company websites, and, in some cases, through direct communication with the vendors. PHM Modules columns indicate which of the six core PHM functions each architecture supports: data acquisition, system modeling, fault detection, diagnostics, prognostics, and advisory generation. The data acquisition column indicates if the product includes modules or interfaces to automatically collect data, either directly from sensors and other sources or by interacting with the existing plant data historian. The last six columns briefly indicate if the platform complies with the six criteria outlined above: open, modular architecture; platform independence; GUI for system development and/or results viewing; web-enabled tools; scalability; and standards compatibility. Where appropriate, brief notes are included to indicate the degree to which a product complies with each criterion. 
Table 2. Features of commercially available integrated health management frameworks.

\begin{tabular}{|c|c|c|c|c|c|c|c|c|c|c|c|c|c|}
\hline \multirow[b]{2}{*}{ Product } & \multirow[b]{2}{*}{ Company } & \multicolumn{6}{|c|}{ PHM Modules } & \multirow[b]{2}{*}{$\begin{array}{c}\text { Open, } \\
\text { Modular } \\
\text { Architecture }\end{array}$} & \multirow[b]{2}{*}{$\begin{array}{c}\text { Platform } \\
\text { Independence }\end{array}$} & \multirow[b]{2}{*}{ GUI } & \multirow[b]{2}{*}{$\begin{array}{l}\text { Web- } \\
\text { Based } \\
\text { Tools }\end{array}$} & \multirow[b]{2}{*}{ Scalability } & \multirow[b]{2}{*}{$\begin{array}{c}\text { Standards } \\
\text { Compatibility }\end{array}$} \\
\hline & & $\begin{array}{c}\text { Data } \\
\text { Acquisition } \\
\end{array}$ & $\begin{array}{c}\text { System } \\
\text { Modeling } \\
\end{array}$ & $\begin{array}{c}\text { Fault } \\
\text { Detection }\end{array}$ & Diagnostics & Prognostics & $\begin{array}{c}\text { Advisory } \\
\text { Generation }\end{array}$ & & & & & & \\
\hline $\begin{array}{l}\mathrm{AOC} \text { and } \\
\mathrm{EHM}\end{array}$ & $\begin{array}{l}\text { Optimized } \\
\text { Systems and } \\
\text { Solutions Inc. } \\
\text { (OSyS) }\end{array}$ & $\mathrm{X}$ & $\mathrm{X}$ & $\mathrm{X}$ & $\mathrm{X}$ & $\mathrm{X}$ & $\mathrm{X}$ & Yes & Unknown & Yes & Yes & Yes & Yes \\
\hline eXpress & $\begin{array}{l}\text { DSI } \\
\text { International }\end{array}$ & & & $\mathrm{X}$ & $\mathrm{X}$ & & $\mathrm{X}$ & Somewhat & $\begin{array}{c}\text { Windows XP } \\
\text { or } 7\end{array}$ & Yes & Yes & Yes & DiagML \\
\hline FAMOS & Scientech & $\mathrm{X}$ & $\mathrm{X}$ & $\mathrm{X}$ & $\mathrm{X}$ & & $\mathrm{X}$ & Somewhat & Windows & Yes & Yes & Yes & No \\
\hline $\begin{array}{l}\text { Watchdog } \\
\text { Agent }\end{array}$ & IMS & & $\mathrm{X}$ & $\mathrm{X}$ & $\mathrm{X}$ & $\mathrm{X}$ & & Somewhat & $\begin{array}{c}\text { Requires } \\
\text { LabVIEW for } \\
\text { development }\end{array}$ & Yes & No & No & Yes \\
\hline MADe & $\begin{array}{l}\text { PHM } \\
\text { Technology }\end{array}$ & & & & & & & No & Unknown & Yes & Unknown & Yes & No \\
\hline Maximo & IBM & $\mathrm{X}$ & & $\mathrm{X}$ & & & $\mathrm{X}$ & Yes & $\begin{array}{c}\text { Linux, } \\
\text { Windows }\end{array}$ & Yes & Yes & Yes & Yes \\
\hline $\begin{array}{l}\text { Multi-Agent } \\
\text { Systems }\end{array}$ & $\begin{array}{l}\text { University of } \\
\text { Strathclyde }\end{array}$ & $\mathrm{X}$ & $\mathrm{X}$ & $\mathrm{X}$ & $\mathrm{X}$ & $\mathrm{X}$ & & Yes & Unknown & No & Unknown & Yes & Unknown \\
\hline $\begin{array}{l}\text { Operational } \\
\text { Insight and } \\
\text { Equipment } \\
\text { Condition } \\
\text { Monitor }\end{array}$ & Matrikon & $\mathrm{X}$ & $\mathrm{X}$ & $\mathrm{X}$ & $\mathrm{X}$ & & $\mathrm{X}$ & Yes & Yes & Yes & Yes & Yes & $\begin{array}{l}\text { OPC, ODBC, } \\
\text { MIMOSA }\end{array}$ \\
\hline OstiaEdge & ESRG & $\mathrm{X}$ & & $\mathrm{X}$ & $\mathrm{X}$ & & & Yes & $\begin{array}{l}\text { Windows, } \\
\text { Linux }\end{array}$ & Yes & Yes & Yes & Unknown \\
\hline $\begin{array}{l}\text { PEP and } \\
\text { PEM }\end{array}$ & $\begin{array}{l}\text { University of } \\
\text { Tennessee }\end{array}$ & & $\mathrm{X}$ & $\mathrm{X}$ & & $\mathrm{X}$ & & Somewhat & $\begin{array}{l}\text { Any OS with } \\
\text { MATLAB } \\
\text { 2009a or later }\end{array}$ & No & No & No & No \\
\hline PlantAPS & SmartSignal & $\mathrm{X}$ & $\mathrm{X}$ & $\mathrm{X}$ & $\mathrm{X}$ & & $\mathrm{X}$ & No & Unknown & Yes & Yes & Yes & No \\
\hline $\begin{array}{l}\text { SignalPro } \\
\text { and } \\
\text { ReasonPro }\end{array}$ & $\begin{array}{l}\text { Impact } \\
\text { Technologies }\end{array}$ & $\mathrm{X}$ & $\mathrm{X}$ & $\mathrm{X}$ & $\mathrm{X}$ & $\mathrm{X}$ & $\mathrm{X}$ & Yes & Unknown & Yes & Unknown & Yes & Yes \\
\hline SureSense & $\begin{array}{l}\text { Expert } \\
\text { Microsystems }\end{array}$ & $\mathrm{X}$ & $\mathrm{X}$ & $\mathrm{X}$ & $\mathrm{X}$ & $\mathrm{X}$ & & Yes & Yes & Yes & No & Yes & $\begin{array}{l}\text { Could be } \\
\text { implemented } \\
\text { by standards- } \\
\text { compliant } \\
\text { plugins }\end{array}$ \\
\hline
\end{tabular}


The reviewed products can be divided into four categories: research tools, PHM system development tools, deployable architectures, and peripheral tools.

Research tools include codes and algorithms that are useful for prototyping new methods, investigating feasibility, or performing small-scale studies. These codes tend to not scale well to full systems and lack the development support necessary for actual implementation.

PHM system development tools include products designed to aid in the development of monitoring systems, but not to run analysis with online data.

Deployable architectures are those systems that appear to be developed to the point to scale to large, complex systems; be fully supported by the vendor for system development and implementation; and include most or all of the modules included in a PHM system.

\subsubsection{Research Tools}

Several of the systems considered are actually research tools, not deployable PHM architectures. The PEM and PEP toolboxes from the University of Tennessee are designed for fast prototyping of monitoring, fault detection, and prognostic models. This is to allow easy comparison across candidate models, to support development of new techniques and algorithms, and to present proof-of-principle for small scale systems. The toolboxes are not written to be robust enough for deployment on an actual system of any scale. Similarly, Watchdog Agent, developed at the Center for Intelligent Maintenance Systems at the University of Cincinnati, provides a set of tools for fast prototyping of monitoring, fault detection and diagnostics, and prognostics algorithms. However, this product is built on LabVIEW and is not expected to scale well to the systems and subsystems that comprise an NPP.

\subsubsection{PHM System Development Tools}

Three products can be considered PHM system development tools: eXpress, Maintenance Aware Design environment (MADe), and PHM Design. eXpress was originally designed as a tool for design assessment and optimization for the purpose of fault detection and diagnostics. It has since evolved with some online capabilities, but its core function remains evaluating a system design, either new or legacy, in terms of diagnostic ability. MADe is a suite of tools with a similar purpose. The MADe suite can be used to simulate system failures, track faults as they progress to failure and propagate through the system, optimize sensor placement for maximum detection and diagnosis, and generate fault symptom patterns based on the failure simulation and chosen sensor suite. Finally, PHM Design can be used to identify appropriate targets for prognostic monitoring, optimize the sensor suite, and evaluate the prognostic and diagnostic coverage of a proposed PHM system. While these tools are not directly useful as PHM systems, they can be used to guide and inform system development for pilot studies.

\subsubsection{Deployable Architectures}

Several products or suites of products represent deployable system monitoring architectures. Five of these architectures do not appear to include prognostic estimates, and it is unclear how easy it would be to incorporate third-party prognostic algorithms: eXpress, FAMOS, Operational Insight and Equipment Condition Monitor, OstiaEdge, and PlantAPS. SureSense includes the full health monitoring suite, but does not provide advisory generation. Both OSyS and Impact provide a pair of tools each that seem to employ all six models when used in tandem: AOC and EHM, and SignalPro and ReasonPro, respectively. Depending on the purpose of the applied system, each of these products has its own advantages and disadvantages, as discussed in Appendix A. 
The multi-agent system approach is very promising for developing an open, modular PHM system which scales to large, complex plants. However, this approach has not yet been developed into a commercially available product.

\subsubsection{Peripheral Tools}

IBM's Maximo is an Enterprise Asset Management tool that has some basic data acquisition and signal thresholding capabilities, as well as engines for identifying appropriate maintenance actions and scheduling. Maximo should not be considered a PHM system; however, it is designed with interoperability in mind. It presents a useful hub for displaying and aggregating the results of third-party systems. In fact, the Matrikon products are designed to communicate with Maximo, and it is expected that other products do or will interact with Maximo in the future. 


\section{SUMMARY AND CONCLUSIONS}

There are an extensive body of knowledge and some commercial products available for calculating prognostics, remaining useful life, and damage index parameters. The application of these technologies within the nuclear power community is still in its infancy. Online monitoring and condition-based maintenance are seeing increasing acceptance and deployment, and these activities provide the technological bases for adding predictive and prognostics capabilities. The three key aspects of implementing a PHM system have been presented and discussed: component/system/structure selection, prognostic algorithms, and prognostics architectures.

Four criteria were presented for component selection: feasibility, failure probability, consequences of failure, and benefits of the PHM system.

The basis for and methods commonly used for prognostics algorithms were reviewed and summarized.

Six criteria for evaluating PHM architectures were presented given: open, modular architecture; platform independence; graphical user interface for system development and/or results viewing; webenabled tools; scalability; and standards compatibility.

Thirteen software products were identified as potentially useful for establishing a PHM program in an NPP. These products were evaluated based on the six criteria using information available from company websites, product brochures, fact sheets, scholarly publications, and direct communication with vendors. The thirteen products were classified into four groups of software: research tools, PHM system development tools, deployable architectures, and peripheral tools. Eight software tools fell into the deployable architectures category. Of those eight, only two employ all six modules of a full PHM system. Five systems did not offer prognostic estimates, and one system employed the full health monitoring suite but lacked operations and maintenance support. Each product is briefly described in Appendix A. Selection of the most appropriate software package for a particular application will depend on the chosen component, system, or structure. Ongoing research will determine the most appropriate choices for a successful demonstration of PHM systems in aging NPPs. 


\section{REFERENCES}

Abernethy, R. B., The New Weibull Handbook, 2nd edn. ISBN 096530620 8. Abernethy, North Palm Beach, 1996.

ASME. Long-Term Operations: The Feasibility of Extending the Life of US Nuclear Facilities to 60 Years and Beyond. July 3, 2010. Final Report to A.P. Sloan Foundation. Grant B2009-23.

Azzam, H., "A Practical Approach for the Indirect Prediction of Structural Fatigue from Measured Flight Parameters," Journal of Aerospace Engineering 211 (G), 1997, pp. 29-38.

Baldwin, T., M. Tawfik, and L. Bond [ed.], "Report from the Light Water Reactor Sustainability Workshop on On-Line Monitoring Technologies," June 10-12, 2010, Seattle, Washington, 2010. INL/EXT-10-19500.

Baruah, P., R. B. Chinnam, and D. Filev, "An Autonomous Diagnostics and Prognostics Framework for Condition-Based Maintenance," 2006 International Joint Conference on Neural Networks, Vancouver, BC, Canada, July 16-21, 2006.

Baybutt, M., C. Minnella, A. Ginart, P. W. Kalgren, and M. J. Roemer, "Improving Digital System Diagnostics Through Prognostic and Health Management (PHM) Technology," IEEE Transactions on Instrumentation and Measurement 58 (2), 2009, pp. 255-262.

Bogdanoff, J. L., and F. Kozin, Probabilistic Models of Cumulative Damage, John Wiley and Sons, New York, 1985.

Bond, L. J., P. Ramuhalli, M. S. Tawfik, and N. J. Lybeck, "Prognostics and Life Beyond 60 Years for Nuclear Power Plants," Proceedings of the 2011 IEEE International Conference on Prognostics and Health Management, Denver, Colorado, June 20-23, 2011.

Bond, L. J. and R. M. Meyer, "Online Monitoring to Enable Improved Diagnostics, Prognostics, and Maintenance," ICI2011 Daejon, Korea: August 21-25, 2011.

Bond, L. J., "Moving Beyond NDE to Proactive Management of Materials Degradation," Belleview, Washington: s.n., July 18-22, 2010, Proceedings of the ASME 2010 Pressure Vessels \& Piping Division PVP Conference, PVP2010-26132.

Bond, L. J., S. R. Doctor, D. B. Jarrell, and J. W. D. Bond, (2008). "Improved Economics of Nuclear Plant Life Management," Proceedings of the $2^{\text {nd }}$ IAEA International Symposium on Nuclear Power Plant Life Management, Shanghai, China, International Atomic Energy Agency, IAEA Paper IAEA-CN-155-008KS (26pp).

Brown, D. W., P. W. Kalgren, C. S. Byington, and M. J. Roemer, "Electronic Prognostics - A Case Study using Global Positioning System (GPS)," Microelectronics Reliability, 47, 2007, pp. 1874-1881.

Byington, C. S., M. Watson, D. Edwards, P. Stoelting, "A Model-Based Approach to Prognostics and Health Management for Flight Control Actuators," Proceedings of the IEEE Aerospace Conference, 2004, pp. 3551-3562.

Cadini, F., "Particle Filtering for Diagnosis, Prognosis and On Condition Maintenance," Milan, 2009.

Carden, E. P. and P. Fanning, "Vibration Based Condition Monitoring: A Review," Structural Health Monitoring 3 (4), 2004, pp. 355-377.

Carey, M. B., and R. H. Koenig, "Reliability Assessment Based on Accelerated Degradation: A Case Study," IEEE Transactions on Reliability, 40 (5) 1991, pp. 499-506. 
Carnahan, D., D. Chung, E. delaHostria, and C. Hoover, "Integration of Production, Diagnostics, Capability Assessment, and Maintenance Information Using ISO 18435," Chicago, Illinois: ISA, 2005, ISA EXPO 2005, October 25-27, 2005.

Catbas, F. N. and A. E. Atkan, "Condition and Damage Assessment: Issues and Some Promising Indices,” Journal of Structural Engineering, 128 (8) 2002, pp. 1026-1036.

Catterson, V. M., E. M. Davidson, S. D. J. McArthur, "Issues in Integrating Existing Multi-Agent Systems for Power Engineering Applications," The $13^{\text {th }}$ International Conference on Intelligent System Applications to Power Systems, Arlington, Virginia, November 2005.

Catterson, V. M., S. E. Rudd, S. D. J. McArthur, and G. Moss, "On-Line Transformer Condition Monitoring Through Diagnostics and Anomaly Detection," The $15^{\text {th }}$ International Conference on Intelligent System Applications to Power Systems, Curitiba, Brazil, November 2009.

Chen, Z. and S. Zheng, "Lifetime Distribution Based Degradation Analysis," IEEE Transactions on Reliability, 54 (1), March 3-10, 2005.

Chinnam, R. B., "On-line Reliability Estimation of Individual Components, Using Degradation Signals," IEEE Transactions on Reliability, 48 (4), 1999, pp. 403-412.

Coble, J. B., "Merging Data Sources to Predict Remaining Useful Life - An Automated Method to Identify Prognostic Parameters," Dissertation, The University of Tennessee, May 2010.

Cornell, E. P., et al., Improving motors for utility applications, Vol. 1, EPRI Research Project 1763-1, Report EL-2678, 1982.

Cox, D. R. and D. Oakes, Analysis of Survival Data, Chapman and Hall, 1984.

Dale, C. J., "Application of the Proportional Hazards Model in the Reliability Field," Reliability Engineering, 10, 1985, pp. 1-14.

Diag-ML, "Why Diag-ML,” http://www.diag-ml.com/Detail.aspx, web page accessed August 2011.

Doebling, S.W., C. R. Farrar, M. B. Prime, and D. W. Shevitz, "Damage Identification and Health Monitoring of Structural and Mechanical Systems from Changes in their Vibration Characteristics: A Literature Review,” Technical Report LA-13070-MS, Los Alamos National Laboratory, 1996.

Elsayed, E. A., and A.C-K. Chen, "Recent Research and Current Issues in Accelerated Testing," Proceedings of the IEEE Conference on Systems, Man, and Cybernetics, 1998, pp. 4704-4709.

Engel, S., B. Gilmartin, K. Bongort, and A. Hess, "Prognostics, the Real Issues Involved with Predicting Life Remaining," Proceedings of the IEEE Aerospace Conference, 2000, pp. 457-469.

EPRI, “On-Line Monitoring Cost Benefit Guide,” Final Report 1006777, 2003.

Esary, J. D. and A.W. Marshall, "Shock Models and Wear Processes," The Annals of Probability 1 (4) 1973, pp. 627-649.

Expert Microsystems, SureSense ${ }^{\circledR}$ Software Suite Overview, 2011.

Ferrell, B. L., "JSF Prognostics and Health Management," Proceedings of the IEEE Aerospace Conference, 1999, pp. 471.

Ferrell, B.L., "Air Vehicle Prognostics and Health Management," Proceedings of the IEEE Aerospace Conference, 2000, pp. 145-146.

Girish, T., S. W. Lam, and S. R. Jayaram, "Reliability Prediction Using Degradation Data - A Preliminary Study Using Neural Network-based Approach," European Safety and Reliability Conference, June 15-18, 2003: Maastricht, The Netherlands. 
Goodman, D., "Prognostic Techniques for Semiconductor Failure Modes," Ridgetop Group, Inc. white paper, 2000, http://www.ridgetopgroup.com/doc/WP-electronic_prognostic_techniques.pdf, web page access August 2011.

Greitzer, F. L., E. J. Stahlman, T. A. Ferryman, B. W. Wilson, L. J. Kangas, and D. R. Sisk, "Development of a Framework for Predicting Life of Mechanical Systems: Life Extension Analysis and Prognostics (LEAP)," International Society of Logistics (SOLE) Symposium, Las Vegas, Nevada, August 30-September 2, 1999.

Greitzer, F. L., and T. A. Ferryman, "Predicting Remaining Life of Mechanical Systems," Intelligent Ship Symposium IV, April 2-3, 2001.

Greitzer, F. L., "Life Extension Analysis and Prognostics (LEAP) Architectures," FY 2001 Laboratory Directed Research and Development Annual Report PNNL, pp. 312-316, 2001.

Guess, F. and F. Proschan, "Mean Residual Life: Theory and Applications," FSU Statistics Report M702. AFOSR Technical Report No. 85-178, June 1985.

Gut, A., "Cumulative Shock Models," Advances in Applied Probability 22 (2) 1990, pp. 504-507.

Hale, P. S., J. R., Arno, R. G., "Survey of Reliability and Availability Information for Power Distribution, Power Generation, and HVAC Components for Commercial, Industrial and Utility Installations," IEEE T. Ind. Appl. 371 (2001) p. 191.

Hale, P. S., J. R., Arno, R. G., "Survey of Reliability and Availability Information for Power Distribution, Power Generation, and HVAC Components for Commercial, Industrial, and Utility Installations," ASHRAE Transaction, Research 107, Part 2, 2001, p. 360.

Hallbert, B., J. J. Persensky, C. Smidts, T. Aldemir, and J. Naser, "Report from the Light Water Reactor Sustainablity Workshop on Advanced Instrumentation, Information, and Control Systems and Human-System Interface Technologies,” INL/EXT-09-16631, 2009.

Hashemian, H. M., "On-line monitoring applications in nuclear power plants. Progress in nuclear Engineering, 53 (2), 2011, pp. 167-181.

Hashemian, H. M., "Wireless sensors for predictive maintenance of rotating equipment in research reactors," Annals of Nuclear Energy, 38 (2-3), 2011, pp. 665-680.

He, D., S. Wu, P. Banerjee, and E. Bechhoefer, "Probabilistic Model Based Algorithms for Prognostics," IEEE Aerospace Conference, 2006, Big Sky, Montana.

Heng, A., S. Zhang, A. Tan, and J. Mathew, "Rotating Machinery Prognostics: State of the Art, Challenges, and Opportunities," Mechanical Systems and Signal Processing, 23, 2009, pp.724739.

Hess, A. and L. Fila, "The Joint Strike Fighter (JSF) PHM Concept: Potential Impact on Aging Aircraft Problems," Proceedings of the IEEE Aerospace Conference, 2002, pp. 3021-3026.

Hines, J. W. and R. Seibert, Technical Review of On-Line Montioring Techniques for Performance Assessment: Volume 1: State-of-the-Art, NUREG/CR-6895, 2006.

Hines, J. W., A. Usynin, and A. Urmanov, "Prognosis of Remaining Useful Life for Complex Engineering Systems," American Nuclear Society International Topical Meeting on Nuclear Plant Instrumentation, Control, and Human-Machine Interface Technologies (NPIC\&HMIT), 2006, Albuquerque, NM.

Hines, J.W., J. Garvey, J. Preston, and A. Usynin, "Empirical Methods for Process and Equipment Prognostics," Tutorial presented at the IEEE Reliability and Maintainability Symposium (RAMS), 2007. 
Hines, J. W. and A. Usynin, "Current Computational Trends in Equipment Prognostics," International Journal of Computational Intelligence Systems 1 (1), 2008, pp. 1-9.

Ho, Y.-C., and D. L. Pepyne, "Simple Explanation of the No Free Lunch Theorem of Optimization," Cybernetics and Systems Analysis, 38 (2), 2002, pp. 292-298.

Hofmeister, J. P., P. Lall, R. Graves, "In-Situ, Real-Time Detector for Faults in Solder Joint Networks Belonging to Operational, Fully Programmed Field Programmable Gate Arrays (FPGAs)," Proceedings of the IEEE AUTOTESTCON, 2006, pp. 237-243.

Hofmeister, J.P., J. Judkins, E. Oritz, D. Goodman, and P. Lall, "Real-time BIST Detector for BGA Faults in Field Programmable Gate Arrays (FPGAs)," Ridgetop Group, Inc. white paper, 2006, http://www.ridgetopgroup.com/doc/WP-RT_BIST_Detector-07.pdf, web page accessed August 2011.

IAEA, "On-line Monitoring for Improving Performance of Nuclear Power Plants Part 2: Process and Component Condition Monitoring and Diagnostics," IAEA Nuclear Energy Series No. NP-T-1.2, 2008.

IAEAa, Report on Advanced Surveillance, Diagnostics, and Prognostics Techniques Used for Health Monitoring of Systems, Structures, and Components in NPPs, 2011, D-NP-T-3.14.

IAEAb, Core Knowledge on Instrumentation and Control Systems in Nuclear Power Plants: A Reference Book, 2011, D-NP-T-3.12.

Impact Technologies, Products \& Capabilities for the Power Generating Industry, 2010.

IMS, “Development of Smart Prognostics Agents," July, 20, 2011, http://www.imscenter.net/Research/core_research/Watchdog_2011.pdf, web page accessed August 2011.

International Organization for Standardization (ISO), Condition Monitoring and Diagnostics of Machines - Data Processing, Communication and Presentation - Part 1: General Guidelines, ISO 13373-1:2003.

ISO, Condition Monitoring and Diagnostics of Machines -- Data Processing, Communication and Presentation -- Part 2: Data Processing, ISO 13374-2:2007.

ISO, Condition Monitoring and Diagnostics of Machines - Data Processing, Communication and Presentation - Part 3: Communication, ISO/DIS 13374-3.

ISO, Industrial Automation Systems and Integration - Diagnostics, Capability Assessment and Maintenance Applications Integration - Part 1: Overview and General Requirements, ISO 18435-1:2009.

ISO, Condition Monitoring and Diagnostics of Machines - Prognostics - Part 1: General Guidelines, ISO 13381-1:2004.

Jarrell, D. B., D. R. Sisk, and L. J. Bond, (2004) Prognostics and Conditioned-Based Maintenance: A New Approach to Precursive Metrics. Nuclear Technology, 145 (3), pp. 275-286

K. S. Jardine, D. Lin, and D. Banjevic, “A Review on Machinery Diagnostic and Prognostics Implementing Condition Based Maintenance," Mechanical Systems and Signal Processing, 20, p. 1483, 2006.

Johnson, B., H. Maxwell, "Predictive maintenance - the effect on a company's bottom line, Part 1 - The Global View", Soc. Machinery Failure Prevention Technology, Proc. 56th MFPT Soc., Virginia Beach, Virginia, 2002a, pp. 453-468. 
Johnson, B., H. Maxwell, "Predictive maintenance - the effect on a company's bottom line, Part 2 Calculating the avoided cost", Soc. Machinery Failure Prevention Technology, Proc. 56th MFPT Soc., Virginia Beach, Virginia, 2002b.. pp. 469-482.

Kacprzynski, G. J., M. J. Roemer, G. Modgil, A. Palladino, K. Maynard, "Enhancement of Physics-ofFailure Prognostic Models with System Level Features," IEEE Aerospace Conference, 2002, Big Sky, Montana.

Kacprzynski, G. J., A. Sarlashkar, M. J. Roemer, A. Hess, and W. Hardman, "Predicting Remaining Life by Fusing the Physics of Failure Modeling with Diagnostis," Journal of the Mineral, Metals, and Materials Society 56 (3), 2004, pp. 29-35.

Kalgren, P. W., M. Baybutt, A. Ginart, C. Minnella, M. J. Roemer, and T. Dabney, “Application of Prognostic Health Management in Digital Electronic Systems," Proceedings of the 2007 IEEE Aerospace Conference, March, 2007, pp. 1-9.

Keller, K., K. Swearingen, J. Sheahan, M. Baily, J. Dunsdon, B. Cleeve, K.W. Przytula, and B. Jordan, "Aircraft Electrical Power Systems Prognostics and Health Management," IEEE Aerospace Conference, 2006, Big Sky, Montana.

Kharoufeh, J. P. and S. M. Cox, "Stochastic Models for Degradation-based Reliability," IIE Transactions, 37, 2005, pp. 533-542.

Koppen, M., "No-Free-Lunch Theorems and the Diversity of Algorithms," Congress on Evolutionary Computation, 1, 2004, pp. 235-241.

Korsah, K, D. E. Holcomb, M. D. Muhlheim, J. A. Mullens, A. Loebl, M. Bobrek, M. K. Howlader, S. M. Killough, M. R. Moore, P. D. Ewing, M. Sharpe, A. A. Shourbaji, S. M. Cetiner, T. L. Wilson, Jr., and R. A. Kisner, Instrumentation and Controls in Nuclear Power Plants: An Emerging Technologies Update, 2009, NUREG/CR-6992.

Kothamasu, R, S. H. Huang, and W. H. Verduin, "System Health Monitoring and Prognostics - A Review of Current Paradigms and Practices," International Journal of Advanced Manufacturing Technology, 28, 2006, p. 1012.

Kumar, D. and B. Klefjo, "Proportional Hazards Model: A Review," Reliability Engineering and System Safety, 44, 1994, pp. 177-188.

Lall, P., M. Pecht, and E. Harkim, Influence of Temperature on Microelectronics and System Reliability, New York: CRC Press, 1997.

Larsen, J. M. ed., "Materials Damage Prognosis," Proceedings of a Symposium of the Materials Science and Technology 2004 Conference, Proc. of Symposium, Materials Science \& Technology, New Orleans, Louisiana, TMS Publication, 2004, p. 360.

Lemoine, A. J., and M. L. Wenocor, “On Failure Modeling,” Navel Research Logistics Quarterly 32 1985, pp. 497-508.

Liao, H., W. Zhao, and H. Guo, "Predicting Remaining Useful Life of an Individual Unit Using Proportional Hazards Model and Logistic Regression Model." Proceedings of the Reliability and Maintainability Symposium (RAMS), 2006, pp. 127-132.

Line, J. K. and N. S. Clements, "A Systematic Approach for Developing Prognostic Algorithms on Large Complex Systems," Proceedings of the IEEE Aerospace Conference, 2005, pp. 1-7.

Liu, J., A. Saxena, K. Goebel, B. Saha, and W. Wang, "An Adaptive Recurrent Neural Network for Remaining Useful Life Prediction of Lithium-Ion Batteries," Annual Conference of the Prognostics and Health Management Society, Portland, Oregon, October 2010. 
Lu, C. J., and W. Meeker, "Using Degradation Measures to Estimate a Time-to-Failure Distribution," Technometrics 35 (2) 1993, pp. 161-174.

Luo, J., M. Namburu, K. Pattipati, L. Qiao, M. Kawamoto, S. Chigusa, "Model-based Prognostic Techniques," IEEE Systems Readiness Technology Conference (AUTOTESTCON), September 2225, 2003, Anaheim, California.

Mallor, F. and J. Santos, “Classification of Shock Models in System Reliability,” Monograf'1as del Semin. Matem. Garc'1a de Galdeano. 27 2003, pp. 405-412.

McArthur, S., S. Strachan, and G. Jahn, "The Design of a Multi-Agent Transformer Condition Monitoring System," IEEE Transactions on Power Systems 19 (4), November 2004, pp. 1845-1852.

MIMOSA, “Open System Architecture for Enterprise Application Inegration” (Online) February 2, 2010. http://www.mimosa.org/?q=resources/specs/osa-eai-v3.2.2, web page accessed August 2011.

Mishra, S. and M. Pecht, "In-situ Sensors for Product Reliability Monitoring," Proceedings of SPIE, Vol. 4755 (2002. pp. 10-19.

Mishra, S., S. Ganesan, M. Pecht, and J. Xie, "Life Consumption Monitoring for Electronics Prognostics," Proceedings of the IEEE Aerospace Conference, 2004, pp. 3455-3467.

Mishra, S., M. Pecht, and D. Goodman, “In-situ Sensors for Product Reliability Monitoring," Proceedings of SPIE, 2006, pp.10-19.

Mighdoll, P., et al., "Improving Motors for Utility Applications,” Vol. 2, EPRI Research Project 1763-1, Report EL-2678 (1982).

MRWG, Motor Reliability Working Group, "Report of large motors reliability survey of industrial and commercial installations, Part I,” IEEE T. Ind. Appl. IA-21 (1985) 853.

MRWG, Motor Reliability Working Group, "Report of large motors reliability survey of industrial and commercial installations, Part II,” IEEE T. Ind. Appl. IA-21 (1985) 865.

Oja, M., J. K. Line, G. Krishnan, R. G. Tryon, "Electronic Prognostics with Analytical Models using Existing Measurands," $61^{\text {st }}$ Conference of the Society for Machinery Failure Prevention Technology (MFPT), April 17-19, 2007, Virginia Beach, Virginia.

Orchard, M., and Vachtsevanos, G., "A particle filtering approach for on-line failure prognosis in a planetary carrier plate," International Journal of Fuzzy Logic and Intelligent Systems, Vol. 7, No. 4, 2007, pp. 221-227.

Orsagh, R., D. Brown, M. Roemer, T. Dabnev, and A. Hess, "Prognostic Health Management for Avionics System Power Supplies," Proceedings of the IEEE Aerospace Conference, pp. 35853591, March 5-12, 2005: Big Sky, Montana.

Park, C. and W. J. Padgett, "Stochastic Degradation Models with Several Accelerating Variables," IEEE Transactions on Reliability 55 (2), 2006, pp. 379-390.

Pecht, M., M. Dube, M. Natishan, R. Williams, J. Banner, and I. Knowles, "Evaluation of Built-in Test," IEEE Transactions on Aerospace and Electronic Systems, 37 (1) 2001, pp. 266-271.

Pecht, M. and A. Dasgupta, "Physics of Failure: An Approach to Reliable Product Development," Journal of the Institute of Environmental Sciences 38 (5) 1995, pp. 30-34.

Pecht, M., D. Das, and A. Ramakrishnan, "The IEEE Standards on Reliability Program and Reliability Prediction Methods for Electronic Equipment," Microelectronic Reliability, 42, 2002, pp. 12591266. 
Peng, Y., M. Dong, and M.J. Zuo, Current Status of Machine Prognostics in Condition-Based Maintenance: a Review. 2010, Int. J. Adv. Manuf. Technol., Vol. 50, pp. 297-313.

Ramakrishnan, A. and M. G. Pecht, "A Life Consumption Monitoring Methodology for Electronic Systems," IEEE Transactions on Components and Packaging Technologies, 26 (3) 2003, pp. 625 634.

Ridgetop Group, “Hot Carrier (HC) Prognostic Cell,” Ridgetop Semiconductor-Sentinel Silicon Library, August 2004.

Roemer, M.J., J. Dzakowic, R.F. Orsagh, C.S. Byington, G. Vachtsevanos, "Validation and Verification of Prognostic and Health Management Technologies," Proceedings of the IEEE Aerospace Conference, 2005, pp. 3941-3947.

SAE International, Prognostics for Gas Turbine Engines, 2008, SAE AIR5871.

Sheppard, J. W., M. A. Kaufman, and T. J. Wilmering, IEEE Standards for Prognostics and Health Management. Salt Lake City, Utah, IEEE, September 8-11, 2008, AUTOTESTCON. pp. 97-103. 10.1109/AUTEST.2008.4662592.

SmartSignal. "Nuclear Power Equipment | Power Plant Streamlining," July 20, 2011, http://www.smartsignal.com/industries/nuclear.aspx, web page accessed July 2011 .

Smith, G., J. B. Schroeder, S. Navarro, and D. Haldeman, "Development of a Prognostics and Health Management Capability for the Joint Strike Fighter," Proceedings of AUTOTESTCON, 1997, pp. 676-682.

Tang, L. C., and D. S. Chang, "Reliability Prediction Using Nondestructive Accelerated-Degradation Data: Case Study on Power Supplies," IEEE Transactions on Reliability 44 (4) 1995, pp. 562 566.

Tobon-Mejia, D. A., K. Medjaher, and N. Zerhouni, "The ISO 1338-1 Standard's Failure Prognostics Process Through an Example," Macau, China, IEEE, 2010, Proceedings of the IEEE 2010 Macau Conference on Prognostics \& System Health Management Conference, hal-00459269.

Urmanov, A., "Electronic prognostics for computer servers" Proceedings IEEE Reliability and Maintainability Symposium, 2007, RAMS '07, January 22-25, 2007, pp. 65-70.

United States. Nuclear Regulatory Commission. "Status of License Renewal Applications and Industry Activities," July 20, 2011, http://www.nrc.gov/reactors/operating/licensing/renewal/applications.html, web page accessed July 2011.

Upadhyaya, B.R., M. Naghedolfeizi, and B. Raychaudhuri, "Residual Life Estimation of Plant Components," P/PM Technology June 1994, pp. 22-29.

Vachtsevanos, G., W. Kim, S. Al-Hasan, F. Rufus, M. Simon, D. Schrage, and J.V.R. Prasad, "Mission Planning and Flight Control: Meeting the Challenge with Intelligent Techniques," Journal of Advanced Computational Intelligence, Vol. 1, No. 1, October 1997, pp. 62-70.

Vachtsevanos, G, F. L. Lewis, M. Roemer, A. Hess, and B. Wu, Intelligent Fault Diagnosis and Prognosis for Engineering Systems. Hoboken, New Jersey, John Wiley and Sons, 2006.

Valentin, R., M. Osterman, B. Newman, "Remaining Life Assessment of Aging Electronics in Avionic Applications," Proceedings of the Annual Reliability and Maintainability Symposium (RAMS), 2003, pp. 313-318. 
Vichare, N., P. Rodgers, V. Eveloy, and M. Pecht, "In Situ Temperature Measurement of a Notebook Computer - A Case Study of Health and Usage Monitoring of Electronics," IEEE Transactions on Device and Materials Reliability 4 (4), December 2004, pp. 658-663.

Vichare, N., and M. Pecht, "Prognostics and Health Management of Electronics," IEEE Transactions on Components and Packaging Technologies, 29 (1), 2006, pp. 222-229.

Walter, R., "Open Systems Architecture for Condition-Based Maintenance (OSA-CBM) Primer," August 2006.

Wang, P. and Vachtsevanos, G. "Fault Prognostics Using Dynamic Wavelet Neural Networks," Journal of Artificial Intelligence for Engineering Design, Analysis and Manufacturing, Vol.15, 2001, pp. 349-365.

White House, "Blueprint for a Secure Energy Future," Washington, DC. March 30, 2011.

Wooldridge, M. J. and N. R. Jennings, "Intelligent Agents: Theory and Practice," Knowledge Engineering Review 10 (2) 1995, pp. 115-152.

$\mathrm{Xu}, \mathrm{D}$. and W. Zhao, "Reliability Prediction using Multivariate Degradation Data," Proceedings of the Annual Reliability and Maintainability Symposium (RAMS), 2005, pp. 337-341.

Yang, K. and J. Xue, "Continuous State Reliability Analysis," Proceedings of the Annual Reliability and Maintainability Symposium (RAMS), 1996, pp. 251-257. 


\section{Appendix A}

\section{Assessment Criteria}




\section{Appendix A Assessment Criteria}

Several commercially available prognostics and health management (PHM) architectures have been identified for possible application NPPs. This appendix discusses each of the products summarized in Section 4.3. Products information was gleaned from available literature and data sheets, which are included in Appendix B, "Survey of Industries Focusing on Maintenance". When possible, direct communication with company representatives provided clarification and additional information. The prognostics architectures are reviewed based on the assessment criteria outlined in Section 4.2. Beyond assessing the degree to which each product meets these criteria, no judgment of the products is made or should be inferred. The products reviewed represent a complete list of the available architectures that would scale to a system of the size and complexity of an NPP to the best of the authors' knowledge. Exclusion of any available product is purely an oversight.

\section{A-1. EHM}

Equipment Health Management (EHM) by OSyS utilizes data collected online and through routine walk-around inspections to perform the major tasks of a PHM system through their Asset Optimization Centre (AOC) framework. Their system is built in five layers: data acquisition, data consolidation, data analysis, data presentation, and risk-based maintenance planning.

AOC includes hundreds of standard interfaces for connecting to a wide variety of online data sources. Additionally, several manual data entry points are available to include information from non-instrumented data, as found condition, and event records. AOC also includes algorithms to ensure that extracted information is reliable and conforms to defined quality standards. This is characterized through a quality index that is assigned to data as it is loaded into the system. This quality index then moves with the data through the system to inform how data is utilized. High quality, high reliability data are given more weight in analysis and decision making, whereas less reliable data and data sources are given less importance.

Data consolidation utilizes existing data historians and SCADA systems. Data are preprocessed to reduce data volume and extract important and useful information from the many, disparate data sources. Preprocessing methods include change detection, frequency spectra analysis, and anomaly detection and isolation. In some cases, only the anomalous data are sent to AOC for further analysis.

The data analysis layer includes system modeling, diagnosis, and prognosis; these steps represent the EHM portion of the full AOC system. OSyS AOC includes the ability to train and evaluate empirical models of nominal system behavior. A library of modeling, analysis, and anomaly detection routines is included that can be configured and applied by the user through a well-defined step by step process. However, if the user has first principle-based models of system operation, these can easily be incorporated in the analysis system through the Analytical Building Framework, which uses MATLAB Simulink to design, develop, and test analytic solutions. Legacy models, third-party models, and other proprietary or separately developed created in other environments can also be easily imported into EHM.

The diagnostic system uses a model-based approach built through a drag-and-drop fusion of analytic methods, modeling techniques, and first-principles knowledge. The diagnostic engine includes an estimated confidence value for the presence of all known machine failure modes, instead of choosing a single, most likely fault mode to display. The system naturally fuses multiple diagnostic techniques to improve confidence in fault detection and diagnoses, thereby reducing false positives and improving confidence that the fault has been correctly diagnosed. 
Prognostic analysis in EHM is relatively immature. Simple regression methods are available for benign trends. State-based prognostic analysis is available based on the results of the diagnostic engine. As faults are detected and diagnosed, and as additional information becomes available, the system moves through appropriate prognostic techniques for the current situation. OSyS continues both fundamental and applied research to improve signal processing techniques and develop prognostic capabilities.

Results of the data analysis are displayed in a collaboration portal, which combines information from OSyS products and other vendors based on commercial open system standards. EHM combines multiple interfaces into this system and allows functions to be accessed simultaneously by multiple users. This environment is based on Microsoft Sharepoint, which allows for a highly flexible and configurable environment.

The OSyS system is completely open, allowing customers to view, analyze, or extract data as they wish. It communicates with any Data Access Specification (OPC) enabled data acquisition system. It is also extensible by integrating proprietary algorithms developed by the user or a third party into the overall system. Additionally, EHM and the OSyS AOC include proven solutions for specific plant components. Several of the available components and failure modes are pertinent to NPP operation, including pump, pipe, and pressure vessel monitoring,

\section{A-2. eXpress}

DSI International provides eXpress ${ }^{\mathrm{TM}}$ tools for diagnostic capability assessment and online diagnostics. eXpress was originally developed to perform design assessment and optimization for diagnostics for both new and legacy designs. This assessment includes the probability of detecting a fault and correctly isolating the cause of the fault. The diagnostic tool has been expanded to also produce a Prognostics Candidate report, which indicates the failure modes that would most benefit from prognostic monitoring. In addition to diagnostic assessment, eXpress also includes plug-ins like Workbench and the Run-Time Authoring Tool. eXpress Workbench is designed to be used by technicians to deploy diagnostics in production and maintenance environments. Workbench can be used to reduce false alarms, isolate and identify a fault, and aid in determining appropriate repair actions. The Run-Time Authoring Tool is a web-based client for displaying the results of eXpress and Workbench. Run-Time Authoring Tool runs on the DiagML standard and facilitates the visual mapping of faults and root causes to elements in the system design. Through this standard, the results of eXpress and Workbench can easily be exported into standard-compliant third-party applications.

The eXpress toolkit is continuously being expanded. The DSI Maintenance Reasoner, expected in 2011, supports real-time diagnostic analysis based on real-world conditions. While prognostics and mission planning are not currently implemented in the eXpress framework, such capabilities are expected in the pending Operation and Support Simulation module.

The eXpress analysis is based on a model of the system or plant developed in a CAD-like graphical user interface (GUI). For a system as large and complex as an NPP, it is recommended that the overall plant be divided into systems and subsystems that can be easily modeled and afterwards be connected to provide the full plant model.

\section{A-3. FAMOS}

The Fleet Asset Management and Optimization Solutions (FAMOS ${ }^{\mathrm{TM}}$ ) suite of products is available from Scientech. FAMOS includes six core modules: PEPSE, PMAX, CMAX, PdP, R*TIME, and Rules Engine. PEPSE is a power plant thermal modeling, design, and performance analysis program currently implemented in all United States' NPPs. PMAX is the online extension of PEPSE that performs thermal performance monitoring, analysis, and optimization. It is currently used in 59 U.S. NPPs for thermal 
performance monitoring. CMAX provides condition monitoring and diagnostics using both online and off-line data. PdP quickly detects and identifies operational, process, and equipment problems based on predictive pattern recognition. $\mathrm{R}^{*}$ TIME provides online data capture and archiving on both a local plant and fleetwide level to support fast, reliable data retrieval and processing. Finally, Rules Engine works across the suite of products for diagnosis and decision support. FAMOS does not currently include any support for prognostics or prognostic-based maintenance planning.

PEPSE and PMAX both focus specifically on plant thermal efficiency assessment and optimization. PEPSE performs a steady-state system analysis for an entire plant, a subsystem, or a specific component. It is used to analyze boundary conditions, assess the effects of plant changes, and optimize thermal performance. PMAX performs online thermal performance monitoring. It also is able to validate incoming data to detection instrument faults and calibration errors.

CMAX monitors equipment condition using both online and offline data. This utility offers continuous monitoring and risk assessment for the overall plant status, comprehensive component condition monitoring, and early warning of equipment degradation. The tool plugs in with the Rules Engine to automatically perform fault diagnosis. The Rules Engine is a rule-based diagnostic system, which includes embedded tools for the user to create and modify rules. These rules can incorporate all available information sources, both online and offline. Pre-configured rules for various common fault conditions are included in a Component Rules Library, but the exact nature and breadth of these rules is not known. Fault warnings are generated based on pre-defined, component-specific critical fault sizes.

PdP is an additional fault detection engine. It utilizes existing data acquisition systems, data historians, and information from other monitoring systems such as PMAX and CMAX. PdP performs fault detection through the traditional monitoring approach. An empirical system model is built based on available historical, nominal data. Expected nominal sensor values are compared to the actual sensor values to characterize how well the system behavior agrees with the expected behavior through residuals. Simple thresholding techniques are applied to these residuals to determine if the system is operating in a nominal or faulted condition.

Several of the core modules of FAMOS include the ability to integrate third party applications. $\mathrm{R}^{*} \mathrm{TIME}$, the data acquisition and data historian tool, allows inclusion of in-house fault detection applications into the full FAMOS suite. FAMOS also has portals for interfacing with other solutions, such as Enterprise Resource Planning (ERP) utilities. The full suite of modules is controlled through a single, web-enabled GUI for easier implementation and training. However, each of the tools can be run separately to provide the specific solutions needed; it is not required that all modules be implemented. The functions available in FAMOS are designed to scale to a complex system such as an NPP. Additionally, it is designed to monitor a system or component, a single plant, or an entire fleet.

\section{A-4. LabVIEW WITH WATCHDOG AGENT}

Watchdog Agent ${ }^{\circledR}$ is a LabVIEW-based toolkit developed by researchers at the Center for Intelligent Maintenance Systems at the University of Cincinnati. The toolkit is scheduled for commercial release in fall, 2011. Because it is based on LabVIEW, the toolkit can run on a variety of platforms including Windows, MacOSX, and Linux, provided that LabVIEW is installed. If LabVIEW is not available, the monitoring system can be developed using Watchdog Agent and LabVIEW, and then compiled to run on any machine. Similarly, the functionality of LabVIEW can be used to convert Watchdog Agent into a web-enabled toolkit; however, web connectivity is not naturally supported.

Watchdog Agent employs a multi-sensor approach to meet four of the OSA-CBM layers: signal processing, condition monitoring, health assessment, and prognostics. The toolbox extracts performancerelated features from inputs of sensor data, controller signals, and expert knowledge, and models 
historical feature values to estimate system health. Over 20 classes of algorithms are included in the Watchdog Agent, as shown in Table A-1. Additionally, Watchdog Agent can integrate third-party or userdeveloped algorithms, provided they are available in a format that is compatible with LabVIEW. Performance, and therefore health, evaluation is performed through a statistical approach that compares the most recent observations and features with those seen during nominal operation. The overlap between the current distribution of signatures and the nominal distribution is called the Confidence Value (CV). As the system health deteriorates, this value trends toward zero. Similarly, if signature distributions are available for faulty conditions, the $\mathrm{CV}$ can be used to determine which fault the system is most likely experiencing. Watchdog Agent is designed to be an adaptable system, able to learn the signatures of new faults as they become available to improve fault detection and diagnostics during future operation. This feature is particularly attractive to aging components which may experience faults not previously seen or considered.

Table A-1. Watchdog Agent ${ }^{\circledR}$ Toolbox algorithms (IMS 2011).

\begin{tabular}{ll}
\hline \multicolumn{1}{c}{ Signal Processing and Feature Extraction } & \multicolumn{1}{c}{ Health Assessment } \\
\hline Time Domain Analysis & Logistic Regression \\
Frequency Domain Analysis & Statistical Pattern Recognition \\
Time-Frequency Analysis & Gaussian Mixture Modeling (GMM) \\
Wavelet/Wavelet Packet Analysis & $\begin{array}{l}\text { Feature Map Pattern Matching } \\
\text { (Self-Organizing Maps) }\end{array}$ \\
Expert Extracted Features & Neural Network Pattern Matching \\
Autoregressive (AR) Model/AR Model Roots & Adaptive Filtering \\
Principal Component Analysis (PCA) & Hidden Markov Model (HMM) \\
\hline \multicolumn{1}{c}{ Performance Prediction } & \multicolumn{1}{c}{ Health Diagnosis } \\
\hline Autoregressive Moving Average (ARMA) & Feature Map Pattern Matching \\
& (Self-Organizing Maps) \\
Elman Recurrent Neural Network & Support Vector Machine (SVM) \\
Match Matrix & Bayesian Belief Network (BBN) \\
Trajectory Similarity Based Prediction & Hidden Markov Model (HMM) \\
Stochastic Filtering & \\
Fuzzy Logic & \\
\hline
\end{tabular}

The layer definitions of the available layers in Watchdog Agent are the same as the generic layer definitions of standards such as MIMOSA OSA-CBM. A full system, which meets the requirements of this standard, could be developed using the Watchdog Agent platform. However, data acquisition and decision making support must be realized by peripheral applications and algorithms outside of the Watchdog Agent system.

To date, Watchdog Agent has not been applied to a system with the size and complexity of an NPP. Watchdog Agent has been applied to vehicle component prognosis, spindle bearing monitoring, machine tool health monitoring, and elevator door monitoring, among others. The system appears to be well-suited to monitoring components or small subsystems, but scalability may prove to be an issue for a system as complex as an NPP or for fleet wide plant monitoring. 


\section{A-5. MADe}

Maintenance Aware Design environment (MADe) is a software tool provided by PHM Technology that models system failures and behavior to identify possible functional issues and mitigate risk during the design process. This product suite is not an integrated PHM system, but it supports PHM system design and development. For that reason, it is briefly reviewed here. The MADe suite of products includes the original MADe studio, MADe RAM, and MADe PHM.

MADe models parts, components, subsystems, and systems to identify and assess potential functional and safety issues in system design. MADe analysis starts with a functional model of the plant built with available components from a generic library or customized components created for specific projects or platforms. System-wide responses to failures are simulated through system hierarchies. This provides automated failure mode tracking through the system hierarchy.

MADe reliability, availability, and maintainability (RAM) utilizes the MADe model to determine design and functional issues that will affect reliability and availability from the line replaceable unit (LRU) level through to the full system level. This package generates fault trees which can be used to drill down from system failures to the associated components and systems which caused or contributed to the failure. This analysis can be used to generate a detailed failure database which has been optimized for RAM functions. These results can be exported to other analysis and decision support tools.

Finally, MADe PHM generates optimal sensor sets for a system based on Failure Modes, Effects, and Criticality Analysis (FMECA) results. Existing or candidate sensor sets can be evaluated, and additional sensors are automatically suggested which can achieve the required coverage and result ambiguity. A library of available sensors and manufacturers allows competing sensor sets to be quickly and easily compared on features such as cost, reliability, etc. The system can accommodate design issues that preclude certain locations for sensors; this is particularly important in the harsh environment of an NPP where some locations simply cannot support sensors or the associated electronics. This package generates a diagnostic symptom set based on the chosen sensor set and simulated system failures, which can be used in other applications, such as a fault detection and diagnostic routine.

While the MADe suite of tools is not suited for analysis of system health or state advisory, it can be used to inform and design such a system. MADe and MADe RAM can be used to better understand fault modes and their effects as they propagate throughout the entire system. MADe PHM can be used to evaluate the efficacy of the available sensor suite for detecting and differentiating fault modes, to suggest optimal sensor types and placement to augment the existing suite, and to generate a list of fault symptoms based on the available sensors, which can be used to develop a diagnostic engine.

\section{A-6. MAXIMO}

Maximo ${ }^{\circledR}$ Asset Management is an enterprise asset management (EAM) hub developed by IBM, which supports management of all types of business assets, including service, contract, materials, procurement, physical asset, and work management. The asset management portion of Maximo allows for monitoring of asset and location conditions to enable proactive maintenance. Condition monitoring interfaces allow for tracking unlimited measurement points. Alarm limits can be specified by the user, as well as maintenance actions associated with alarms for preventative maintenance. Maximo is designed to enable fleet-wide monitoring of components, equipment, or full systems.

Beyond simple signal thresholding for fault detection, Maximo does not seem to include any advanced prognostic or health management routines. However, as a web-enabled platform, PHM systems from third-party providers can be incorporated into Maximo through cut-and-paste functionalities. 
Currently, Matrikon's PHM solutions are designed to tie in with Maximo. Maximo can be integrated with plant-based data acquisition systems and hardware to support condition-based maintenance systems.

IBM offers a software suite specialized for application in the nuclear industry called Maximo for Nuclear Power. This version of the EAM tool includes industry-specific enhancements that correspond to goals such as scalability and standardization. It incorporates key best-practices outlined in the Standard Nuclear Performance Model, including equipment reliability (AP-913) and configuration control (AP-929).

\section{A-7. MULTI-AGENT SYSTEMS}

Multi-agent systems (MAS) provide a promising approach to the problem of information fusion for health monitoring (McArthur et al. 2004; Catterson et al. 2005; Catterson et al. 2009). An agent is defined by Wooldridge (1995) as software that displays autonomy, reactivity, pro-activeness, and social ability. Autonomy in this sense means that the agent operates in an unsupervised mode. Reactivity and pro-activeness refer to the agents' ability to react to surroundings and take action to solve problems so that they may continue to perform their task. Finally, agents are able to cooperate and communicate with other agents, giving them social ability. A multi-agent system employs a collection of agents that operate independently, but cooperatively, to achieve the system goal. Separate agents can be developed for each task in the monitoring system, including data collection and pre-processing; multiple independent monitoring, anomaly detection, and diagnostic routines; corroboration of results from anomaly detection and diagnostic routines; appropriate prognostic modules for each fault type; and result reporting. Often, no one routine is best for detecting and diagnosing all possible faults; each routine is well suited to a subset of the possible faults. The multi-agent approach is attractive because it is inherently extensible to include many disparate fault detection and identification routines. As new routines are developed and refined, they can be easily added to the system by the development of appropriate agents. Additionally, the corroboration agent can account for the differences in accuracy of each of the independent fault detection and diagnostic modules. By considering the "confidence" of each test result, the final diagnosis will account for the inherent uncertainty in each of the diagnostic modules; a framework for this corroboration is given in (McArthur et al., 2004). For optimum remaining useful life (RUL) accuracy, separate prognostics models are used for each possible fault type. These models may or may not employ the same modeling algorithm. In fact, different prognostic model types may be appropriate for different fault modes, depending on the information that can be collected concerning the fault. The estimated RUL is then used for operation and maintenance planning to minimize unnecessary maintenance and inoperation failure, which may be employed by even another agent or group of agents.

The MAS approach has not been implemented in commercially available software, but it presents an architecture for the PHM system, which can easily be designed to meet all the requirements and criteria outlined. MAS-based PHM systems have been studied at the University of Strathclyde for condition monitoring of large transformers using ultra-high frequency data (McArthur et al., 2004). Their system is inherently modular, with separate agents for each task, including data handling agents, isolation agent, classification agents, corroboration agent, engineer assistant agent, etc. The modular nature of the system makes it particularly attractive for combining with agents that perform fault detection and diagnostics based on other information, such as dissolved gas analysis (DGA) or Supervisory Control and Data Acquisition (SCADA) results (Catterson et al. 2005). The developed online monitoring system was deployed on two transformers nearing end of life (Catterson et al. 2009). This system used data collected from $50+$ sensors to detect and diagnose anomalies. The MAS system was shown to be flexible and extensible to incorporate output from other monitoring and interpretation techniques.

No commercially available MAS-based PHM software has been identified; however, this approach is promising as a prognostics architecture due to its inherent ability to incorporate and consolidate information from many different, sometimes conflicting, modules. 


\section{A-8. OPERATIONAL INSIGHT AND EQUIPMENT CONDITION MONITOR}

Two products from Matrikon ${ }^{\mathrm{TM}}$ are pertinent to the area of PHM: Operational Insight and Equipment Condition Monitor. Operational Insight is a web-based data visualization and Key Performance Indicator (KPI) dashboard. Equipment Condition Monitor uses both real-time and historical data to predict, diagnose, and prevent critical equipment failures. Both products are built on the Open operations and maintenance standard which combines OPC data communication standards and MIMOSA compatibility standards.

Operational Insight provides data integration, KPIs, and visualization from existing data acquisition and historian systems. Using OPC-based communication technology, Operational Insight is able to connect to any data source through over 500 OPC interfaces. The software includes trending tools to monitor and analyze plant conditions; graphical presentations built through drag-and-drop creation; both ad-hoc and automated report generation to present important data as it is needed; and comprehensive charting ability to visualize data and KPIs. Complex calculations are also supported across data sources through a graphical calculation tool.

While Operational Insight provides the data aggregation and visualization capabilities, Equipment Condition Monitor performs equipment health monitoring. Equipment Condition Monitor connects to multiple data sources simultaneously through the same OPC protocols and identifies corrupt and missing data. Inferential models are used to perform sensor validation using existing plant knowledge and data resolution. Entire processes and systems are continuously monitored to detect, diagnose, and prevent potential failures. Operations and maintenance requirements are prioritized according to the results of the detection and diagnosis.

Matrikon offers operational excellence guidance specifically for power generation. This program includes solutions in maintenance and reliability, productivity and efficiency, safety and compliance, and environmental management. The productivity and efficiency toolset include solutions for equipment monitoring such as the Equipment Condition Monitor, alarm management, control asset performance management, and centralized monitoring across the entire fleet. Matrikon is a first and second level support partner for IBM's Maximo product.

\section{A-9. OstiaEdge}

OstiaEdge ${ }^{\mathrm{TM}}$ is a suite of monitoring tools provided by Engineering Software Reliability Group (ESRG). OstiaEdge provides plant level or fleetwide monitoring of equipment health through the webbased Ostia Portal. OstiaEdge Plant Edition (PE) monitors a single plant or system, while OstiaEdge Central Edition (CE) combines the results of multiple OstiaEdge PE systems for a fleetwide assessment of health.

OstiaEdge PE compliments and integrates with the plant's existing data historian to integrate both online and offline data sources, including sensed data, control system information, vibration monitors, etc. OstiaEdge "qualifies" data for various user-specified machine states. By identifying the state of the system, unique rule sets can be applied specific to that system state. User-defined machine state algorithms are used to trigger alarms and collect data on events as they unfold.

The OstiaEdge suite operates on a Windows or Linux platform, both for system development and operation. The web-based results portal presents information on machinery run hours, alarms, trends, and events. Event data can be plotted and trended to glean additional information. 


\section{A-10. THE PEM AND PEP TOOLBOXES}

Two MATLAB-based toolboxes have been developed by the Prognostics and Reliability Optimization and Control Technologies (PROaCT) Lab at the University of Tennessee. The Process and Equipment Monitoring (PEM) Toolbox provides functionality for automated system monitoring and fault detection. The Process and Equipment Prognostics (PEP) Toolbox supports fast prototyping of a variety of prognostic algorithms. It is important to note that the PEM/PEP toolboxes are not commercially available products. The toolboxes are intended for research purposes and are maintained for such use. They are not deployable as a standalone health monitoring system.

The PEM and PEP toolboxes are currently implemented as command-line MATLAB functions. Some GUI support is provided in the PEM toolbox for preliminary functions such as variable grouping. Both toolboxes make use of MATLAB structures for model development and analysis. The toolboxes are designed to work together, with an independently developed diagnostic model, to offer a full health monitoring system as shown in Figure A-1.

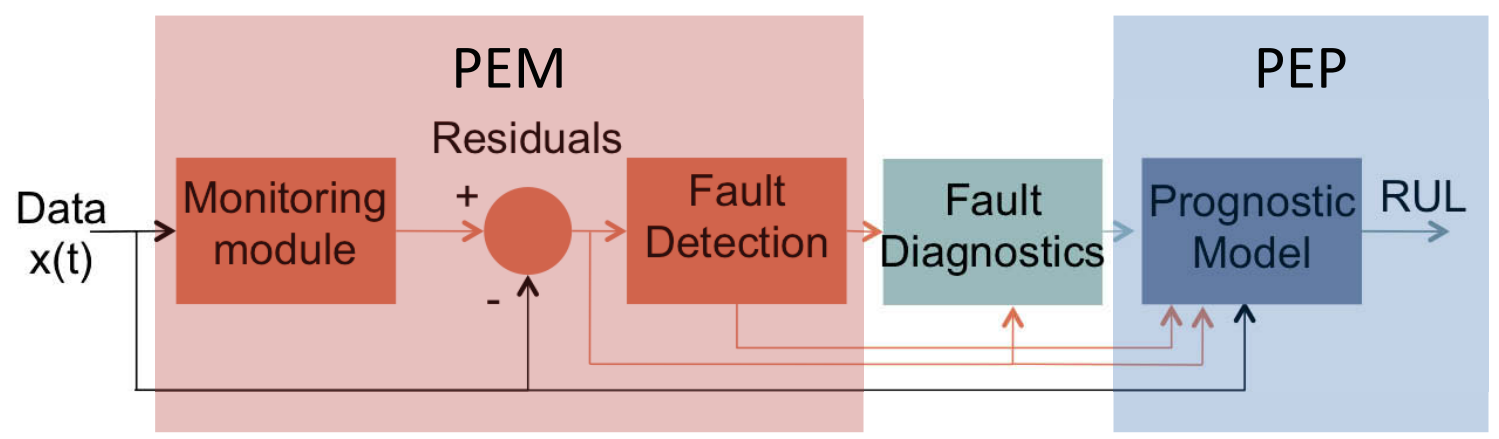

Figure A-1. Integration of the PEM and PEP toolboxes.

\section{A-10.1 Process and Equipment Monitoring Toolbox}

The PEM Toolbox is a MATLAB based set of tools that currently provides a generalized set of functions for use in process and equipment monitoring applications, specifically online monitoring systems (OLM). The current architecture of the PEM Toolbox is organized into six function categories as shown in Figure A-2. The first category allows for data to be acquired from multiple sources and conditioned to assure data quality. The next category includes tools to aid in model development including variable grouping and multivariate model optimization. Several model types are supported by PEM, including auto associative kernel regression (AAKR), auto associative neural networks (AANN), and linear regression models. Once a model is developed, functions for parameter prediction and performance analysis are available to compare competing models. The final two function categories provide methods for uncertainty estimation and fault detection. 


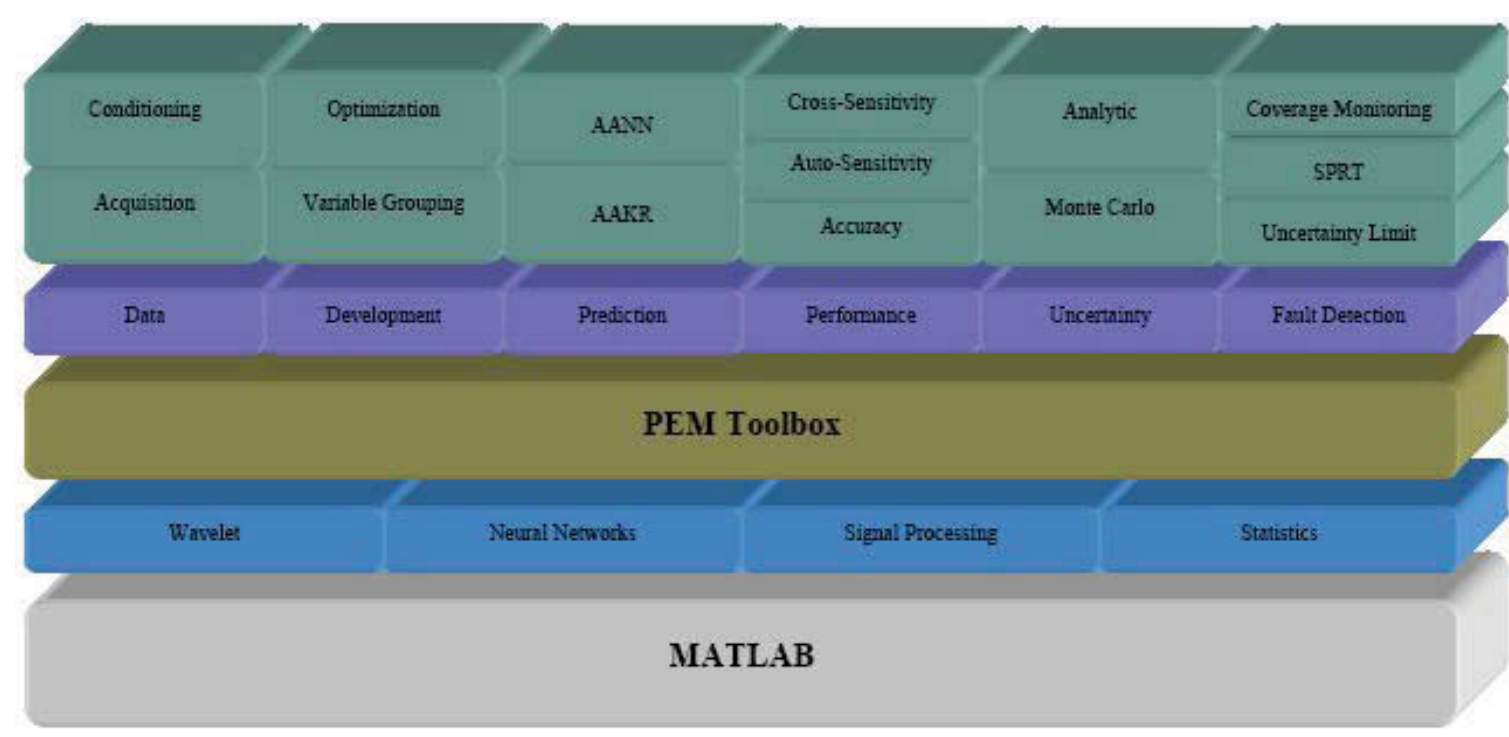

Figure A-2. PEM toolbox architecture.

\section{A-10.2 Process and Equipment Prognostics Toolbox}

The purpose of the PEP toolbox is to provide a complete set of tools to facilitate prognostic model development. A myriad of prognostic algorithms have been developed that use a variety of information sources, models, data processing algorithms, etc. Typically, prognostic model development depends highly on the expertise of the developer. The PEP toolbox reduces the development burden on the system designer and facilitates the rapid development of competing models. As described earlier, prognostic algorithms can be classified by the type of information used to make RUL estimates. Algorithms in each of the three classes are included in the PEP toolbox, along with associated estimates of uncertainty. The PEP toolbox architecture is shown in Figure A-3.

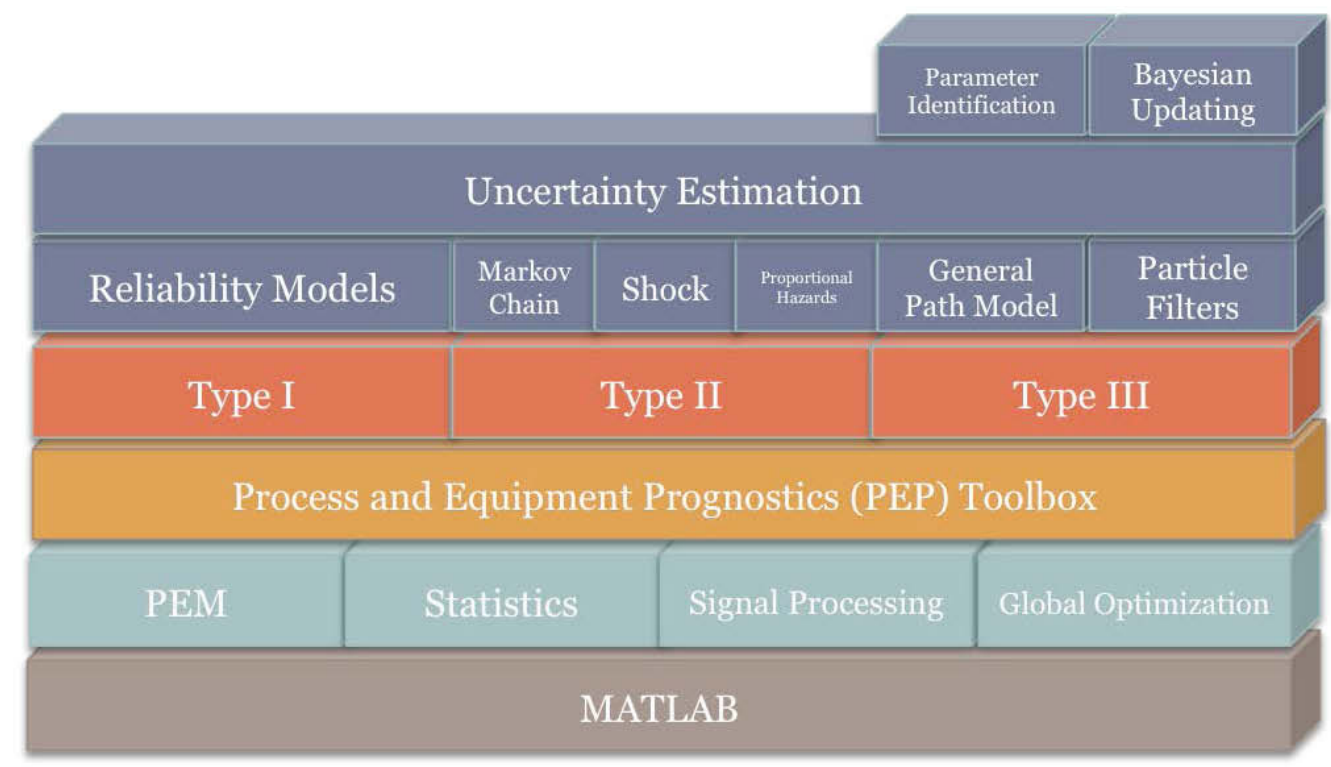

Figure A-3. PEP toolbox architecture. 


\section{A-11.PlantAPS}

SmartSignal's ${ }^{\circledR}$ Plant Availability and Performance Solution (PlantAPS ${ }^{\mathrm{TM}}$ ) combines the monitoring and fault detection power of EPI*Center with the diagnostic solution of SHIELD. EPI*Center interacts with a plant's existing data historian to monitor a system with the data-based Multivariate State Estimation Technique (MSET) algorithm developed at Argonne National Laboratory. SHIELD, the diagnostic engine, leverages SmartSignal's repository of operating information collected over hundreds of millions of machine hours on a variety of systems. This historical data was used to generate symptom patterns which describe tens of thousands of failures captured by SmartSignal. SHIELD uses these fault patterns, in combination with operating data and information, to diagnose faults and assign a "priority" to the faults. The fault priority gives an indication of the severity of the fault, aiding in scheduling maintenance and corrective action. An apparent disadvantage of the SHIELD approach to diagnostics is its inflexibility in defining fault symptoms. Symptoms are based on the data available in the SmartSignal database, and there is no indication that these can be tailored to a specific plant or augmented with additional information, expert knowledge, or independently developed symptom patterns. Currently, SHIELD is able to detect faults in equipment pertinent to NPPs, including boiler feed pumps and other generic pumps, condensers, cooling water circuits, generators, and steam turbines. Figure A-4 lists the failure modes that have been detected and identified by SmartSignal in NPPs.

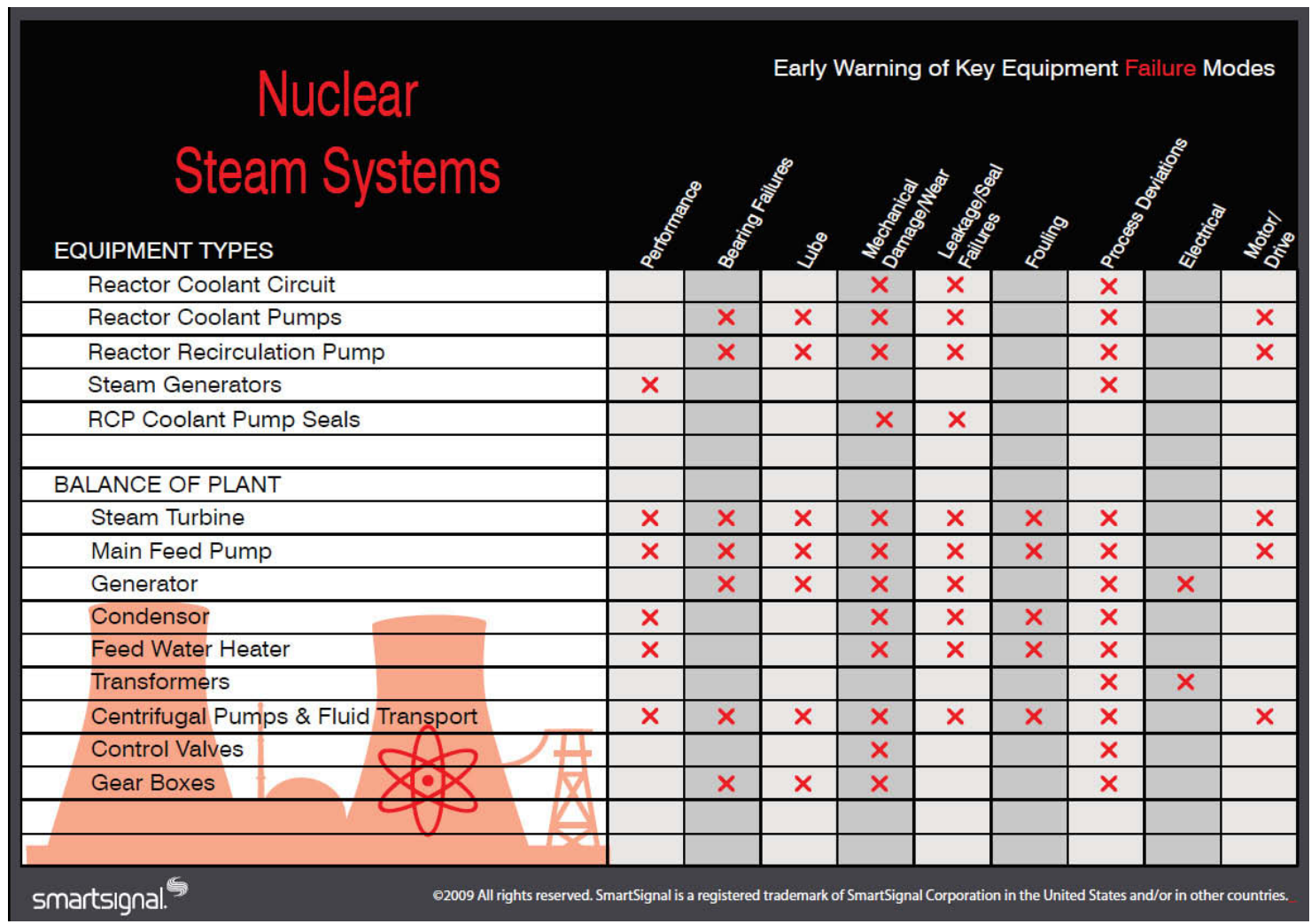

Figure A-4. NPP failure modes detected by SmartSignal (2011).

PlantAPS is a centralized monitoring suite which interacts with the plant's existing Distributed Control System (DCS) or OSI PI infrastructure to perform the monitoring, fault detection, and fault diagnostic tasks available in EPI*Center and SHIELD. PlantAPS is managed and maintained by SmartSignal on their servers. It provides web-based communication of impending plant faults and failures through e-mail notification of key plant personnel. The system can be hosted onsite by the utility, but the 
particulars of this are not clear. The program does not seem to be extensible or modular in anyway; there is no indication that it would be easy or even possible to incorporate third-party algorithms.

\section{A-12. SignalPro and ReasonPro}

Impact Technologies offers a variety of products and tools that are applicable to the nuclear power industry (Impact Technologies 2010). Several of these products are geared to specific components within the plant. $\mathrm{CBMi}^{\mathrm{TM}}$ performs real-time monitoring of critical equipment based on vibration data. BearingLife ${ }^{\mathrm{TM}}$ and ImpactLife ${ }^{\mathrm{TM}}$ work together to monitor and detect failure modes in ball and roller bearings, such as spalling, pitting, and corrosion. GearLife ${ }^{\mathrm{TM}}$ fuses design, monitoring, and operational information with a finite element fatigue model to prognose the remaining useful life of gears. They have also developed custom solutions for steam turbines. Two of their products are more generally applicable to health monitoring: SignalPro ${ }^{\mathrm{TM}}$ and ReasonPro ${ }^{\mathrm{TM}}$.

SignalPro is an anomaly detection system built on a data-driven system modeling engine that effectively increases the signal to noise ratio of sensed data. In this way, it looks for subtle changes in system behavior, such as instrument faults or system degradation. SignalPro can be used in systems with high variability in expected nominal measurements due to changes in operating condition such as load or season. SignalPro can be implemented alone or in conjunction with existing data historians and condition monitoring systems.

ReasonPro is a model-based diagnostic and prognostic reasoning software. It captures both evidenceand temporal-based relationships between fault symptoms and failure modes to provide robust fault isolation and identification. Because causality (temporal) information is considered, fault propagation to failure can be analyzed based on associated PHM monitor sequences. ReasonPro has been developed to run in multiple settings - online for real-time system monitoring, on mobile devices for walk-around analysis, and offline for test stands and post analysis applications.

\section{A-12.1 IMS and PBMS}

In addition to the monitoring and diagnostic software, Impact Technologies offers two products to aid in condition-based maintenance scheduling. The Impact Maintenance Scheduler (IMS ${ }^{\mathrm{TM}}$ ) uses machinery health information, estimates of RUL, and Enterprise Resource Planning (ERP) information to determine the optimal maintenance actions and schedule in order to maximize readiness and/or minimize cost. The Prescription Based Maintenance Management System $\left(\mathrm{PBMS}^{\mathrm{TM}}\right)$ intelligently ranks maintenance tasks based on the likelihood of success and the effects to cost and downtime. PBMS incorporates information from PHM systems in determining which failure modes are most likely and most important, indicating which maintenance tasks are most pressing. Both IMS and PBMS are built on open system architecture to facilitate collaboration with PHM and logistics systems.

\section{A-12.2 PHM Design}

The PHM Design ${ }^{\mathrm{TM}}$ tool aids in designing, developing, evaluating, and deploying PHM and CBM systems. Much like the MADe suite of products, this tool is not an online PHM engine. It is a development tool to aid in designing a system using information from a FMECA, the current sensor suite, and visual system design. PHM Design can identify the most appropriate components or system for PHM monitoring based on fault risk; evaluate the prognostic coverage of the proposed system for catastrophic failures; and evaluate the ability to correctly isolate and identify faults using the available sensors and information. In addition to designing and evaluating a PHM system, PHM Design can autogenerate aspects of the final system from existing databases, such as a fault isolation system using a generic reasoner and the Extensible Markup Language (XML) database. 


\section{A-13. SureSense}

SureSense ${ }^{\circledR}$ is the health monitoring research and development framework provided by Expert Microsystems (EM). SureSense is built on EM's Diagnostic Monitoring Studio software, which is a highly-customizable java-based architecture that supports modular plug-in of any of EM's proprietary models or any third-party or customer proprietary models. The software suite displays results through a user-designed HMI screen, with data visualization and plotting tools, and a data export feature to move results into another system as desired.

This is not a web-enabled tool; it is workstation based and is designed with the system engineer in mind. The suite is not designed for fleet-wide monitoring, but scales to a full nuclear power plant model. Because of the plug-in nature of the software package, compliance to standards such as OPC and MIMOSA is straightforward. Data acquisition and data reporting modules can be easily developed to meet these criteria.

The SureSense architecture is based on five hierarchical levels of data analysis, including data validation, state prediction, fault detection, diagnostic decision, and prognostic decision, as shown in Figure A-5. The software can interface with any existing data acquisition system through the included universal data acquisition interface. The data validation layer, also called data qualification, uses filters and data conditioning tools to ensure data quality. SureSense also uses this stage to optionally identify equipment's operating conditions to apply mode partitioning for condition-specific modeling. Mode partitioning reduces false and missed alarms caused by nominal changes in plant characteristics due to seasonal operating changes or characteristics of equipment aging. The state prediction layer generates the expected system operating conditions using an appropriate first-principle or empirical model, which can be one from the bank of available models or an independently developed third-party plug-in model. The actual data collected from the system and the expected data generated in the state prediction layer are compared in the third layer, fault detection. Fault detection routines include simple thresholding, range monitoring, noise estimation, derivative tests, the sequential probability ratio test (SPRT), and the EM proprietary Adaptive Sequential Probability test. If a fault is detected, the fourth layer attempts to diagnose the type of fault using a Bayesian Belief Network, which can be developed through a drag-and-drop interface. Finally, the system moves to the prognostic decision layer, which can make estimates of RUL at any point in the system's life based on the information currently available such as runtime, fault detection and diagnostic results, and system data. As indicated, the system is fully customizable at each layer by the use of third-party or customer developed proprietary models, which fit into the java-based Diagnostic Monitoring Studio framework. 


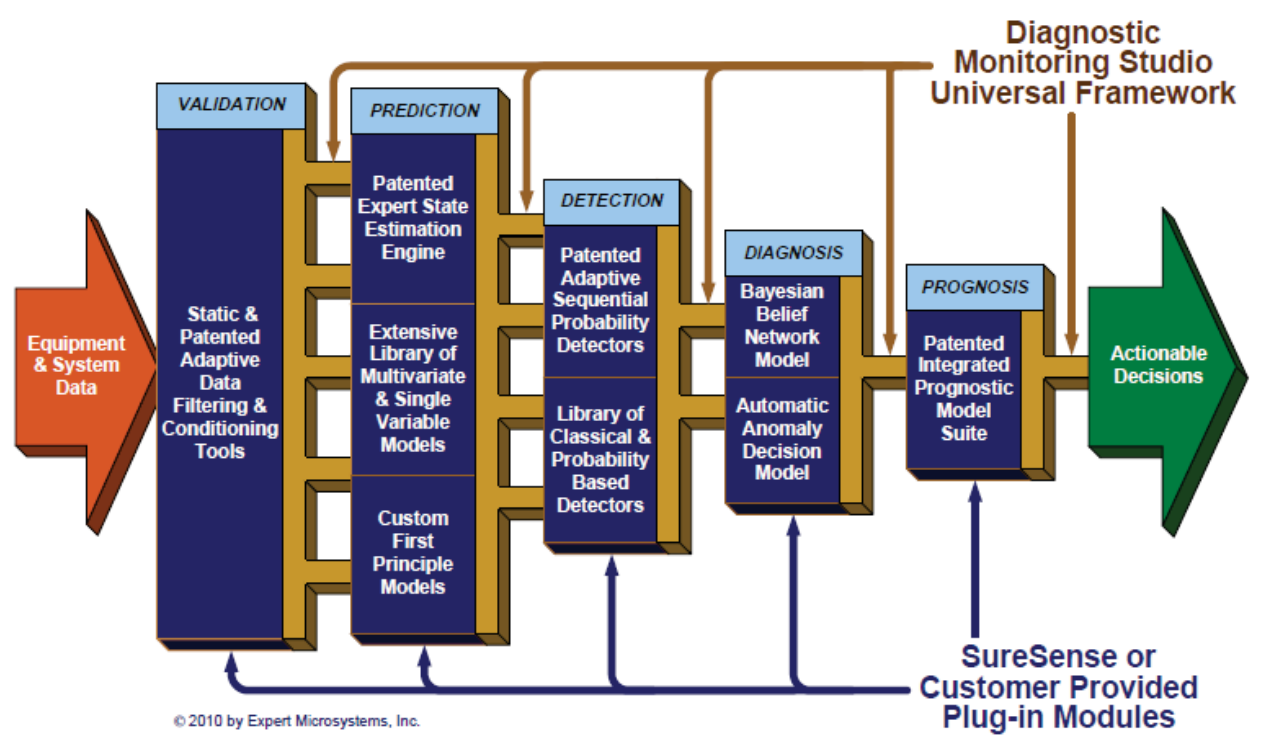

Figure A-5. SureSense architecture (expert microsystems).

SureSense has been used at power generation plants including NPPs in the U,S. and abroad. Most notably, it has been employed by Tennessee Valley Authority, Excelon Energy, South Carolina Electric and Gas, and British Energy for sensor calibration interval extension and performance-critical equipment monitoring. EM is currently partnered with Constellation Energy for a pilot study applying the SureSense suite for monitoring tendon slips and breaks in the containment structure at Ginna Nuclear Power Plant in Ontario, New York. They are also engaged in studies using fiber optic sensors to monitor and detect flow-induced corrosion in steam ducts. 


\section{Appendix B}

\section{Survey of Industries Focusing on Maintenance}




\section{Appendix B}

Table B-1. Survey of industries focusing on maintenance (from Kothamasu et al. [2006]).

\begin{tabular}{|c|c|c|c|c|}
\hline Company & Capability & Software & Application & Modeling Technique \\
\hline $\begin{array}{l}\text { Smart Signal } \\
\text { www.smartsignal.com }\end{array}$ & $\begin{array}{l}\text { - Sensor data analysis } \\
\text { - Empirical modeling } \\
\text { - Offline/online }\end{array}$ & $\begin{array}{l}\mathrm{eCM} 2.0 \text { (run-time engine, } \\
\text { database, watchlist manager) }\end{array}$ & $\begin{array}{l}\text { Aviation, power plant, } \\
\text { commercial transportation }\end{array}$ & $\begin{array}{l}34 \text { patented algo- } \\
\text { rithms (statistical and } \\
\text { time-series) }\end{array}$ \\
\hline $\begin{array}{l}\text { Data Systems and Solu- } \\
\text { tions } \\
\text { www.ds-s.com }\end{array}$ & $\begin{array}{l}\text { - Specialized oil analysis systems } \\
\text { (JetScan) } \\
\text { - Mostly offline }\end{array}$ & $\begin{array}{l}\text { CETADS for engine diagnosis, } \\
\text { asset management software, } \\
\text { CAFTA for fault tree analysis }\end{array}$ & $\begin{array}{l}\text { Aviation, hydraulic systems. } \\
\text { continuous production systems }\end{array}$ & Neural networks \\
\hline $\begin{array}{l}\text { Science Applications In- } \\
\text { ternational } \\
\text { www.saic.com }\end{array}$ & $\begin{array}{l}\text { - Inspection automation } \\
\text { - Ultrasonic analysis }\end{array}$ & $\begin{array}{l}\text { IDEAS (data analysis), C-SCAN } \\
\text { (inspection automation) }\end{array}$ & $\begin{array}{l}\text { Aviation. industrial safety and } \\
\text { security }\end{array}$ & Neural networks \\
\hline $\begin{array}{l}\text { IVARA } \\
\text { www.ivara.com }\end{array}$ & $\begin{array}{l}\text { - Reliability centered mainten- } \\
\text { ance }\end{array}$ & IVARA.ERS (expert system) & UNKNOWN & Expert systems \\
\hline $\begin{array}{l}\text { Aladon } \\
\text { www.aladon.co.uk }\end{array}$ & $\begin{array}{l}\text { - Reliability centered mainten- } \\
\text { ance solutions }\end{array}$ & RCM toolkit (report generation) & UNKNOWN & Statistical \\
\hline $\begin{array}{l}\text { EMA INC } \\
\text { www.ema-inc.com }\end{array}$ & $\begin{array}{l}\text { - Control system engineering } \\
\text { - CMMS solutions } \\
\text { - Information technology }\end{array}$ & $\begin{array}{l}\text { SCADA (supervisory control } \\
\text { and data acquisition) }\end{array}$ & $\begin{array}{l}\text { OEM. food processing, medi- } \\
\text { cal, communications }\end{array}$ & $\begin{array}{l}\text { Statistical, alarm gen- } \\
\text { eration }\end{array}$ \\
\hline $\begin{array}{l}\text { FLIR Systems, INC } \\
\text { www.flir.com }\end{array}$ & $\begin{array}{l}\text { - Predictive maintenance } \\
\text { - Infra red cameras for mainten- } \\
\text { ance } \\
\text { - Automation equipment } \\
\text { - OEM applications and research }\end{array}$ & $\begin{array}{l}\text { Infrared data analysis and re- } \\
\text { porting software }\end{array}$ & $\begin{array}{l}\text { Paper. food. steel, petrochemi- } \\
\text { cal industries }\end{array}$ & NO MODELING \\
\hline $\begin{array}{l}\text { AssetPoint } \\
\text { www.tabware.com }\end{array}$ & $\begin{array}{l}\text { - Data acquisition and open sys- } \\
\text { tems storage } \\
\text { - Enterprise asset management }\end{array}$ & Tabware (CMMS application) & $\begin{array}{l}\text { Petrochemical, OEM continu- } \\
\text { ous production systems }\end{array}$ & NO MODELING \\
\hline $\begin{array}{l}\text { BE\&k } \\
\text { www.bek.com }\end{array}$ & - Maintenance solutions & UNKNOWN & $\begin{array}{l}\text { Paper \& pulp mining, tele- } \\
\text { communications power, } \\
\text { chemical and processing }\end{array}$ & Statistical \\
\hline $\begin{array}{l}\text { DRM Technologies } \\
\text { www.drmtech.com }\end{array}$ & $\begin{array}{l}\text { - Lean manufacturing } \\
\text { - maintenance solutions }\end{array}$ & NO SOFTWARE & UNKNOWN & NO MODELING \\
\hline $\begin{array}{l}\text { General Physics Corpora- } \\
\text { tion } \\
\text { www.gpworldwide.com }\end{array}$ & $\begin{array}{l}\text { - Predictive maintenance } \\
\text { - Equipment reliability improve- } \\
\text { ment }\end{array}$ & NO SOFTWARE & $\begin{array}{l}\text { Aviation, paper \& pulp, } \\
\text { telecommunications, high-tech, } \\
\text { food \& beverage }\end{array}$ & Statistical \\
\hline $\begin{array}{l}\text { HSB Reliability technolo- } \\
\text { gies } \\
\text { www.hsbrt.com }\end{array}$ & $\begin{array}{l}\text { - World class reliability } \\
\text { - Total plant reliability } \\
\text { - Preventable maintenance } \\
\text { - CMMS solutions } \\
\text { - Root cause failure analysis }\end{array}$ & $\begin{array}{l}\text { NO SOFTWARE (partners with } \\
\text { IVARA) }\end{array}$ & UNKNOWN & UNKNOWN \\
\hline $\begin{array}{l}\text { Reliasoft } \\
\text { www.reliasoft.com }\end{array}$ & $\begin{array}{l}\text { - Reliability assesment } \\
\text { - FMEA }\end{array}$ & $\begin{array}{l}\text { Weibullt+, Blocksim, Xfmea, } \\
\text { RG }\end{array}$ & & $\begin{array}{l}\text { - Weibull analysis } \\
\text { - Simulation }\end{array}$ \\
\hline
\end{tabular}

